\title{
PHARMACEUTICAL HISTORY AND ITS SOURCES IN THE WELLCOME COLLECTIONS. II. DRUG WEIGHING IN BRITAIN, c. 1700-1900
}

by

\author{
J. K. CRELLIN AND J. R. SCOTT
}

THIS STUDY, which is based partly on the very important collection of eighteenth/ nineteenth-century English scales and weights in the Wellcome Institute of the History of Medicine, is particularly concerned with the question of accuracy of weighing. Much relevant information comes from the scales and weights themselves and the wide range of examples is detailed largely by way of illustrations and an appendix. ${ }^{1}$ These details, besides being of considerable interest to the antiquary and the social historian, throw light on the confusion that could readily result from the concurrent use in pharmacies of avoirdupois, troy, and apothecaries weights. ${ }^{2}$ Many problems on weights and measures remain to be solved and it is hoped that a knowledge of the wide-ranging Wellcome Collections will stimulate study (for a note on measures, which are not the concern of this paper, see footnote 37$)^{3}{ }^{3}$

Though Kisch has given recently a certain amount of information on dispensing scales and weights his account appears to be largely based on the situation in certain Continental countries. Certainly the British scene did not match the ideal conditions

1 Note on terms used in this study:

Scales, without further qualification, refer both to the beam and the pans, though for much of the period under consideration the term 'scales' was restricted to the pair of pans, the whole being referred to as 'beam and scales'.

Troy and apothecaries systems. It is often stated that the troy and apothecaries systems are one and the same. This is incorrect for though the grain and the ounce are the same in both systems, there is no denomination for 'scruple' and for 'drachm' weights in the troy system, or 'pennyweight' in the apothecaries system.

Drachm and dram. The difference in spelling is not always indicative of difference in meaning. As a modern convention, 'drachm' is commonly reserved for the apothecaries weight (1/8 of an ounce of $\mathbf{4 8 0}$ grains) and 'dram' for one-sixteenth of the avoirdupois ounce of $\mathbf{4 3 7 . 5}$ grains; yet during the period under consideration 'dram' seems to have been most frequently used for the apothecaries weight. The spelling 'drachm' has been used to indicate 60 grains throughout this study, irrespective of the original spelling.

It should be noted that the Dublin Pharmacopaia of 1850 divided the ounce avoirdupois into eight parts, thus producing a 'drachm' of $\mathbf{5 4 . 6 8}$ grains and a 'scruple' of 18.22 grains.

2 During the period under consideration there were many debates on the dangers of using weights of different denominations but with the same name, e.g., troy ounce and avoirdupois ounce. One solution to the problem frequently spoken of was the metric system, but the perennial discussions over the different systems of weights used in pharmacy are not considered in this paper.

As will be indicated in various footnotes the range of the Wellcome Collections extends beyond that of direct relevance to the subject of pharmaceutical metrology. Nevertheless in many instances the non-pharmaceutical items provide important background information, for example, in connection with verification stamps on weights, and in the construction of weighing instruments. The subject of British weights and measures is largely unstudied as can be seen from this paper and from Libra, the publication of the recently formed Weights and Measures History Circle.

British pharmaceutical metrology, in particular, has received little attention, but for recent helpful discussions see, for instance, F. G. Skinner, 'The history of troy and apothecaries weight', Alchemist, 1952, 16, 155-60; G. Griffenhagen, 'Tools of the apothecary', J. Am. Pharm. Assn., (Pract. Ed.)., 1956, 27, 152-53, 240-41 ; L. G. Matthews, History of Pharmacy in Britain, Edinburgh and London, 1962 , various pages. 


\section{J. K. Crellin and J. R. Scott}

- to include government control-implied by Kisch until after the far-reaching, reforming Weights and Measures Act of 1878." Nevertheless, this paper will try to show that before this the eighteenth- or nineteenth-century apothecary, chemist and druggist, or scientific chemist ${ }^{5}$ could, if he were careful in the purchase, testing and maintenance of his scales and weights, feel confident that he was using satisfactory and sometimes first-class equipment in spite of totally inadequate schemes of inspection. For instance, because there were no national standards until 1879, there was neither independent verification after manufacture nor periodic inspection of drachm and scruple apothecaries weights. ${ }^{6}$

Strangely, however, there were standards for apothecaries grain and ounce weights as these were also 'imperial' weights (i.e. weights in the troy or avoirdupois systems ${ }^{7}$ ). Nevertheless ounce weights were only rarely stamped and inspected (see p. 59), though, in contrast, grain weights were frequently verified because of their use for weighing coin and bullion (see p. 54) and it is perhaps fortunate that many of these latter stamped weights were also used in dispensing medicines. However, much of the vigilance over grain weights was probably often offset because most scales (not only pharmaceutical) were not independently checked (that is, were not given verification stamps) until after 1889 , although local inspection was a long established practice. $^{8}$

\section{VERIFICATION AND INSPECTION: AVOIRDUPOIS AND TROY WEIGHTS}

Although the long, complex story of inspection and verification stamping of both avoirdupois and troy weights (used in pharmacy along with apothecaries weights,

- See B. Kisch, Scales and Weights, New Haven and London, 1965, especially pp. 7, 140-45, and 211-13.

${ }_{5}^{5}$ There is no doubt that, except for analysis (cf. footnotes 56 and 57), scales and weights similar to those used for dispensing were commonly used for chemical work during the eighteenth-nineteenth centuries. A description of a hand scale for chemists is given on p. 60, and a simple hand scale on a pillar is illustrated, for instance, in F. Accum's A Practical Treatise on the Use and Application of Chemical Tests, London, 1820, plate 1 (cf. fig. 9b). John Dalton's scales (including a bench model which was bought from Accum) are discussed by K. R. Farrer in 'Dalton's Scientific Apparatus', (John Dalton and the Progress of Science, ed. by D. S. L. Cardwell, Manchester, 1968, pp. 159-86).

There is only one pair of scales among the portable chemical chests in the Wellcome Collections (for some information on these chests see Ambix, 1967, 14, 60). The scales are of the hand type with swan-neck beam ends (see appendix).

- Standards for apothecaries weights and measures came into force by an Order in Council of 14 August 1879 under the 1878 Act to Consolidate the Law Relating to Weights and Measures (41 and 42 Vict. Ch. 49).

In 1825 the troy pound was made legal standard as a result of the 1824 Act for Ascertaining and Establishing Uniformity of Weights and Measures; under the same Act standards for various troy and avoirdupois weights were created; these include troy ounce and grain weights. The grain, it should be remembered, is the same unit in both the avoirdupois and troy systems.

Standards for decimal grain weights - formerly used in scientific work and possibly occasionally in dispensing (see footnote 56)-were legalized by an Order in Council of 16 August 1870. The avoirdupois pound which was, in 1824, defined in terms of the troy pound was legalized in 1855 as the primary pound standard of 7,000 grains. The troy pound was abolished by the 1878 Weights and Measures Act.

8 Verification stamping of scales was enacted by the 1889 Act for Amending the Law Relating to Weights and Measures, and for other purposes connected therewith (52 \& 53 Vict. Ch. 21). Inspection of scales has a long history involving jurisdiction by Court leet and other local authorities; only in 1795 was it included in national legislation by the Act for the more effectual Prevention of the Use of defective Weights, and of false and unequal Balances. It should be noted that bismars apparently bearing pre-1878 verification stamps are known, but the reason for the stamp can, at present, only be conjectured (cf. footnote 59). 


\section{Drug Weighing in Britain, c. 1700-1900}

see below) remains to be fully studied, the main features can readily be told. ${ }^{9}$ Verification stamping in London is especially significant because many London verified weights were in use throughout the country. A particularly important period was the first quarter of the seventeenth century; this saw the extension of the powers of the Plumbers Company in inspecting and sizing lead and iron weights, resulting in the availability of large numbers of stamped weights. ${ }^{10}$ By 1700 , however, the use of lead weights-prone to inaccuracy because of the softness of the metal-was declining, in favour of those in brass though Guy's Hospital was still buying them in 1725, some possibly for the apothecary. ${ }^{11}$ (See footnote 12 for reference to the Wellcome lead weights.) In the face of this declining use of lead weights, the Founders Company, which had the power of stamping and inspecting brass weights, was the major influence during most of the period under consideration. The widespread impact-at least in connection with avoirdupois weights-of the Founders' stamp (which was the ewer, often accompanied by the crowned Royal monogram ${ }^{13}$ ) was recognized by the Corporation Commissioners in 1837 when they stated that

\footnotetext{
- The only attempt to concentrate attention on verification stamps on weights appears to be T. Brewer's 'On the antiquity of marking and stamping weights and measures' (J. Brit. Arch. Ass., $1853,8,309-322)$. One of the urgent problems in British metrology is the identification of many pre-1878 verification stamps. That the Wellcome Collections provide many problems can be seen from figs. 3, 4, 6, 7, 8 .

${ }_{10}^{10}$ See G. J. A. Robinson, 'The Worshipful Company of Plumbers', Libra, 1962, 1, 10-11.

11 Bill of Richard Court dated 23 June 1725, in Guy's Hospital Archives. The bill is of considerable interest in that it lists a large number of scales and weights supplied to the hospital shortly after its foundation. It includes two 'piles of lead weights'.

A second bill, dated 8 September 1725, from Robert Hoe 'in Loathbury' lists other scales and weights. These-which include hand scales-are more likely to have been intended for the apothecary's shop. This unique bill is as follows:
}

\section{Bought of Robert Hoe in Loathbury ye 8 Septem 1725}

One pr of Large Copper Counter Scales with Lines hooks \& buttons one pr of 7 pound Copper Scales with Brafs Chaine \& a Round Beam ye Best Sort for a pr of Large hand Scales with Brafs Chane \& a Round Beam ye Beft Sort one pr Ditto Lefser with Silk Strings

one pr of Small ye Beft Sort

one Sett of Brafs waits from 4 pound down to a quarter of an ounce

one $14 f$ one $7 f$ pound Iron waite

one Box

two Setts of Drams \& grains

One Large Beam \& Scales ye Beft Sort

two Iron halfe hundred wts, at 13s pr hundred

One quarter Ditto att

$$
\begin{aligned}
& £ \quad s . \quad d . \\
& 1=4=6 \\
& 1=0=6 \\
& 0=10=6 \\
& 0=4=3 \\
& 0=3=6 \\
& 0=9=6 \\
& 0=3=6 \\
& 0=0=10 \\
& 0=1=0 \\
& 1=4=0 \\
& 0=13=0 \\
& 0=4=0 \\
& \hline £ 5=19=1
\end{aligned}
$$

We are grateful to Mr. Orde (Archivist) and the Board of Governors of Guy's Hospital, for allowing us to consult this and other bills in the possession of the hospital.

13 Weights made of lead, pewter, or other soft material, were not to 'be stamped or used' following the 1835 Act to Repeal an Act of the Fourth and Fifth Year of His present Majesty relating to Weights and Measures, and to Notice other Provisions instead thereof (5 \& 6 Will. IV, Ch. 63). Because of this, and the low survival rate of weights constructed with soft metal, relatively few lead weights have survived. Of the few examples in the Wellcome Collections the most unusual are the small lozengeshaped weights illustrated in fig. $5(w-x)$. These bear the denominations 120 GRS/DRA: 2, and 407 GRS. The significance of $\mathbf{4 0 7}$ grains is unknown.

Two examples from a pile of crudely-made avoirdupois lead weights (of denominations, $1 \mathrm{lb}$. $1 \mathrm{lb}$., $4 \mathrm{oz}$., $2 \mathrm{oz}$. are shown in fig. 6e). One of these weights has the denomination $(2 \mathrm{oz}$.) scratched rather than impressed onto the surface suggesting the possibility that the weight was 'home-made'. Pieces of lead found occasionally in scale and weight boxes likewise suggest the fairly common ad hoc use of lead for weighing - perhaps as a counterpoise for a container.

${ }^{18}$ For some information on the tens of thousands of weights stamped by the Founders Company, see G. J. A. Robinson, Libra, 1962, 1, 18-20. 


\section{J. K. Crellin and J. R. Scott}

Notwithstanding that the limits of the jurisdiction only extend to the city and three miles compass thereof, the weights stamped at the hall of the company have been generally circulated and used throughout the United Kingdom, during more than 200 years. ${ }^{14}$

It should also be mentioned that from at least the early seventeenth century avoirdupois weights after receiving the Founders Company stamps were further marked ('sealed') with the City of London Arms at Guildhall (see fig. 6), and that from the 1750s the City of Westminster introduced its own stamping.

The availability of stamped avoirdupois weights (which certainly did not do away entirely with grossly inaccurate weights ${ }^{16}$ ) is particularly relevant to the present story, because avoirdupois weights (not troy or apothecaries weights) were used both for the retail sale of drugs and for the preparation of large quantities of medicaments. In 1859 Wilson, reviewing this development, commented that:

The larger denominations of troy weights . . . actually disappeared from many

establishments and [fell] into total disuse in many others, comparatively few Druggists were left who complied with the directions of the Colleges in compounding their Galenical preparations directly by these weights: by far the greater number adopted a process of transmuting the quantities so as to express them in the avoirdupois weights. ${ }^{17}$

That this practice, which was well established by the eighteenth century, ${ }^{18}$ was widespread is underlined by tables for converting troy weights into avoirdupois, such as can be found in Redwood's edition of Gray's Supplement to the Pharmacopaia (London, 1847).

The Founders Company stamped troy as well as avoirdupois weights, though, from the evidence that large numbers of unstamped troy weights survive, it seems that the verification of many of these specialized weights (only used in pharmacy, and by goldsmiths, silversmiths, jewellers and pawnbrokers), went by default despite the greater care over those for coin and bullion. ${ }^{10}$ This care is illustrated by legislation,

\footnotetext{
14 Quoted by T. Brewer, op. cit., (footnote 9), p. 320.

16 Just when Guildhall 'sealing' of weights, which had received the Founders Company stamp, commenced is uncertain, but provision for it was included in an Ordinance of the City of London in 1613 and confirmed in the 1614 Charter of the Founders Company granted by James 1 of England. (see W. N. Hibbert, History of the Worshipful Company of Founders of the City of London, London, 1925.) Stamping in Westminster was introduced through An Act to explain, amend and render more effectual an Act passed in the Twenty-ninth Year of the Reign of His present Majesty, entitled An Act for appointing a sufficient number of Constables for the Service of the City and Liberty of Westminster; and to compel proper persons to take upon them the office of Jurymen to prevent nuisances and other offences within the said City and Liberty (23 Geo. II, Ch. 17).

${ }_{10}$ There is much contemporary evidence for this in Commissions of Inquiry and reports such as Report from the Select Committee on the Weights and Measures Act; together with the Minutes of Evidence, House of Commons, 17 June 1835.

${ }_{17} \mathrm{C}$. Wilson, 'Observations on a proposed adjustment of weights and measures for the new British Pharmacopocia', Pharm. J. Trans., 1859-60, 1, (2), 18-28.

${ }_{18}$ This is emphasized in Wilson's account largely by his mention of the attempts to reform through the 1746 London Pharmacopaia, but there is similar evidence in other sources, such as H. Pemberton's A Course of Chemistry, London, 1771, pp. 58-62. Pemberton took a great interest in weights (cf. ibid., p. xxii) and he clearly had much to do with the attempts to reform weights and measures in the London Pharmacopeia (cf. also footnote 35).

10 The absence of verification stamps applied particularly to nested troy weights (see below, p. 59).
} 
enacted in 1774 despite the objections of the Founders Company, ${ }^{20}$ whereby weights for coins were to be verified by a 'stamper' appointed by the Crown and it is clear that large numbers of weights were stamped under this legislation. ${ }^{21}$ There is also evidence that assay offices outside London stamped weights for coins though the extent of this is unknown. ${ }^{22}$

Likewise just how much provincial stamping of both avoirdupois and troy weights was undertaken has not been ascertained. There was, of course, legislation for verification by local authorities, but there has been no adequate study of surviving weights; ${ }^{23}$ nor has there been consideration of complications such as indicated by John Warner in 1814: 'the makers of brass weights in Birmingham and other places in these Kingdoms, stamp and seal [weights] themselves, which leads to many inaccuracies'. . $^{4}$

Such fraudulent practices were not unknown in London, as the Founders Company discovered on more than one occasion. ${ }^{25}$ The question of the effectiveness of verification is further complicated by doubts on the accuracy of some of the 'official' stamping; certainly a few stamped grain weights in the Wellcome Collections are grossly inaccurate. ${ }^{26} \mathrm{John}$ Warner informed the 1814 Select Committee that 'there is a Public Office in Westminster, where they stamp all weights that are brought to them, whether just or not; and have been in this practice for many years. I have now in my possession many weights of different sizes, some too heavy, others too light, all stamped at the Westminster Office, without their being put into scales. ${ }^{27}$

But, by way of contrast to this stricture, the Westminster authority, on one occasion at least, was apparently vigilant over grain weights used by chemists and druggists. In 1856 some Westminster chemists and druggists were prosecuted, under $A n$ Act for Regulating the Weights used in Sales of Bullion, for not using stamped grain

${ }^{30}$ A petition by the Founders Company against the stamping of coin weights by the Mint is recorded in Journals of the House of Commons, 1754, 14, 807. Despite losing this appeal the Founders Company did stamp troy coin weights such as pennyweights. There are a number of examples in the Wellcome Collections with the Founders Company stamp of the ewer (cf. fig. 6).

31 Details of the stamper's activities are discussed by G. P. Dyer, 'The Office of Stamper of Money Weights, 1774-1880', Libra, 1966, 5, 20, et seq. in various issues.

In the statement of the stamper's activities in the London Gazette (e.g., 13-17 Dec., 1774), John Whitehurst, the first stamper, announced that he would stamp weights of 12 grains, 6 grains, 3 grains, and 1 grain among others. The stamp was the imperial crown. Whitehurst (1713-85) was an important eighteenth-century instrument maker and it is of interest that he made assay balances. (See E. G. R. Taylor, The Mathematical Practitioners of Hanoverian England 1714-1840, Cambridge, 1966.)

${ }_{22}$ We are grateful to Mr. J. S. Forbes, deputy warden, Goldsmiths Company for this information about stamping by assay offices. Documentary proof has not been found but weights are known bearing assay office stamps (cf. fig. $8 \mathrm{c}$ ).

${ }_{23}$ As mentioned the study of pre-1878 local verification stamps requires urgent study. One publication with some relevant information is H. C. Dent's Old English Bronze Wool Weights, Norwich, 1927. It is pertinent to add that the Wellcome Collections include three previously unrecorded George I wool weights. There is also information on verification stamps in various issues of Libra, 1962, vol. 1 to date.

"Report from the Select Committee on Weights and Measures, ordered by the House of Commons to be printed, 1 July 1814, p. 13. John Warner, Jr. repeated the charge in 1834 stating that weights 'undergo a sort of forged stamping, to induce people to believe they have been stamped' (Minutes of Evidence taken before the Select Committee on the Bill to amend and render more effectual two Acts of the Fifth and Sixth years of the Reign of his late Majesty King George the Fourth relating to Weights and Measures, 1834, p. 47).

${ }_{23}$ See evidence quoted in W. N. Hibbert, History of the Worshipful Company of Founders of the City of London, London, 1925, pp. 114-16.

30 At least six examples have an error of more than 25 per cent overweight.

27 Op. cit., (footnote 24), p. 12. 


\section{J. K. Crellin and J. R. Scott}

weights. ${ }^{28}$ An appeal was lodged by John Bell \& Co. on the grounds that the Act did not apply to dispensing: Jacob Bell was reported to say that: '[he] had not been able to discover any provision in any Act of Parliament [relating to pharmacy] which resolved this difficulty, and having taken every precaution to insure accuracy by employing a respectable scale-maker and having all his weights periodically examined, he claimed the indulgence of the Court. ${ }^{29}$

In spite of the justice of this view, John Bell \& Co. lost their case, and it would seem that for a number of years subsequently, all grain weights used in Westminster were stamped, though not those of scruple and drachm denominations. ${ }^{30}$

If verification stamping left much to be desired, periodic inspection was equally diverse and open to abuse. Provision for systematic inspection was first made in 1795, a progressive move which was developed by the appointment of 'inspectors' under Acts of 1834-35. ${ }^{31}$ Nevertheless, this did not do away completely with such longstanding practices as control by courts leet, constables, and local officialdom, and there is no doubt that inspection varied considerably from area to area until the 1878 Weights and Measures Act, a situation underlined as late as 1869 by the Commission inquiring into the condition of the Exchequer Standards (see footnote 32).

\section{APOTHECARIES WEIGHTS: A STARTLING RANGE OF INACCURACY}

With this rather laissez-faire background in mind (but which occasioned some inspection of chemists' and druggists' shops, see below), it is not altogether surprising that the absence of stringent inspection of pharmaceutical weights-so different from certain Continental countries-did not generally trouble the medical and the pharmaceutical professions. ${ }^{33}$ But this does not mean there was no interest in accuracy. There was at times considerable concern which perhaps now seems out of proportion to the comparatively few potent drugs available until the isolation of active principles in the nineteenth century. This concern was reflected, for example, in the dispensing of liquids, in posology, and in the gradual disappearance of such quantities as a

28 See report in Pharm. J. Trans., 1855-56, 15, 485.

${ }^{20} \mathrm{Ibid}$. Jacob Bell, also stated that "chemists [were] under the jurisdiction of the [Royal] College of Physicians in regard to weights and measures', and hence claimed exemption from the liability to being summoned for possessing weights below six grains not stamped with the Westminster stamp.

${ }^{30}$ It was apparently construed from the Court case that drachm and scruple weights were also to be stamped, but the Westminster stamper of weights and measures refused to stamp them on the grounds that he had no standards, Pharm. J. Trans., 1856-57, 16, 108.

31 The 1795 Act for the more effective Prevention of the Use of defective Weights, and of false and unequal Balances enacted that 'persons to examine weights and balances ... once in every month at the least' were to be appointed by Justices at the Quarter Sessions. 'Inspectors' of Weights and Measures were fully established by Acts of 1834-35.

32 The Commission recommended that 'the authority over the verification and inspection of weights and measures in Great Britain be withdrawn from the control of all Corporations of Cities, Town Councils of Municipal Boroughs, Courts of Burgesses, Universities, Lords of Manors and Court Leet, Ward Inquests, Parish Vesteries, and other such corporations and persons in which it is now invested by statute, charter, custom, or local Act, and be transferred to the county magistrates, except in such of the more important and populous cities and boroughs as Parliament may determine'. (See Fourth Report of the Commissioners appointed to Inquire into the Condition of the Exchequer (now Board of Trade) Standards on the Inspection of Weights and Measures etc., London, 1870, p. xxi).

23 There are only occasional instances when inadequate weighing is noticed such as in connection with antimonial and mercurial preparations; for example, W. Hawes' An Account of the late Dr. Goldsmith's Illness, London, 1774, pp. 11-12.

The greater Continental concern is refiected in publications listed in Kisch, op. cit. (footnote 4). Additionally should be noted H. Zana, Lances et Pondera Servant, University of Paris, 1965, which outlines the important role of French pharmacists in the general inspection of weights. 
handful and a pugil (one-eighth of a handful). ${ }^{34}$

The dispensing of liquids is largely irrelevant to the present story as they were often measured by volume; however, liquid galenicals were generally sold by weight, and some authors, especially during the eighteenth century, did not always make it clear whether they were weighing or measuring fluids. ${ }^{35}$ The weighing of liquids certainly had its advocates, for around the turn of the eighteenth century the Dublin and Edinburgh Pharmacopaias introduced the practice which survived until well into the nineteenth century. ${ }^{36}$ This certainly overcame the problem of dispensing by 'drops', an unsatisfactory procedure solved in the London Pharmacopaia of 1809 by the use of minim measures. ${ }^{37}$

The interest in posology, especially in giving doses graded according to age, received expression in the small booklets accompanying home medicine chests. Such booklets are also relevant to the story in that they stressed the denominations of and the symbols for apothecaries weights which were unfamiliar to members of the general public who used them in home dispensing. This information was also frequently copied on to slips of paper which were either kept in the scale box or stuck

st Such quantities were generally used for measuring dried herbs. They appear in, for instance, J. Quincy, Pharmacopaia Officinalis \& Extemporanea, or A Compleat English Dispensatory, London, 1719.

${ }^{35}$ The confusion in the eighteenth century over measuring and weighing is discussed, for example, in H. Pemberton's The Dispensatory of the Royal College of Physicians, London, Translated into English with Remarks, etc., London, 1746, pp. 43-45. A good example of possible confusion can be seen in Brown Langrish's Physical Experiments upon Brutes, London, 1746, particularly his section 'Physical Experiments with the Lauro-cerasus'. On one occasion at least (p. 86) he seems to have given the cherry-laurel water by weight, but whether he consistently did so is not clear. This is in spite of the fact that Langrish generally took great care over experimental details as is noted by M. P. Earles, 'The introduction of hydrocyanic acid into medicine, a study in the history of clinical pharmacology', Med. Hist., 1967, 11, 305-13.

Galenical preparations were sold by weight in tared bottles until at least the beginning of this century. That this was being practised in the eighteenth century - when bottles were not accurately standardized -is indicated in, for instance, Timothy and Sylvanus Bevan's bill for pharmaceutical preparations for Guy's Hospital during 1733 (in the Guy's Hospital Archives). The bill lists unusual quantities for liniments and tinctures etc. (e.g., $6 \mathrm{lb} .13 \mathrm{oz}$. fs.) suggesting that they were sold by weight in a tared vessel. Unfortunately there are no examples in the Wellcome Collections of 'bottle scales', which were advertised during the nineteenth century.

${ }^{36}$ D. L. Cowen, ('The Edinburgh Pharmacopœia', Med. Hist., 1957, 1, 123-39) has emphasized that weighing was introduced into the 1783 Edinburgh Pharmacopaia and that for most liquids it survived until 1839. Cowen also notes that the 1792 edition made an allowance for wine, water and watery fluids which might be measured in special glass graduates which indicated the corresponding weights. A notice in the pharmacopoia stated that such glass measures were available from the Edinburgh Glass-House Company and principal druggists and apothecaries of the city. None of these measures appears to have been recorded.

${ }^{37}$ For the London Pharmacopeia of 1809 , the Royal College of Physicians adopted the glass measures invented by Timothy Lane (British Patent no. 2511, 1801), for which the standard wine gallon of the Exchequer was divided into 61,440 parts ('minims').

As Matthews (History of Pharmacy in Britain, Edinburgh and London, 1962, pp. 280-81) points out, it is difficult to find evidence for the use of graduated glass measures much before the end of the eighteenth century; certainly insufficient numbers are available to assess accuracy and so make a comparison with weighing.

However, horn measures such as the one illustrated by Matthews (ibid., plate XXIII) were commonly in use before glass measures and, judging from some 50 two-ounce examples in the Wellcome Collections, they were reasonably accurate, suggesting that such measures were perhaps less erratic than weights. Unfortunately, however, it is not possible to say whether these are all eighteenth-century measures, for some were certainly produced during the nineteenth century, as Savory \& Moore supplied them for military use. (We are grateful to L. G. Matthews for the latter information.)

The Wellcome Collections include a wide range of pewter and other measures for larger volumes than the horn measures allowed. They are of the types used both in pharmacy and elsewhere; a list of these is available on request. 


\section{J. K. Crellin and J. R. Scott}

to the inside of the lid. Such an emphasis possibly helped to counteract any tendency to error in home dispensing which must, from time to time, have occurred. ${ }^{38}$

Yet the generally unsatisfactory state of inspection and verification stamping must have often vitiated warnings about the need for careful weighing of drugs; it is less likely that scales and weights bought for home dispensing were checked on purchase as were many of those used in chemists' and druggists' shops (see below). There is, for instance, in the large Wellcome Collection of medicine chests a two-drachm weight marked two scruples (see fig. 10) and a 'troy' ounce weight weighing 437.5 grains, though this does not mean there were no serious errors in the scales and weights used in pharmacies. ${ }^{39}$ It is no wonder that Theophilus Redwood stated, in 1881, that if 'I were asked to point out a direction in which British pharmacy, with all its modern improvements, has manifested little or no progress and was much behind the existing state of pharmacy abroad and the advanced state of science and art in this country, I should refer to the imperfect arrangements adopted for ensuring accuracy of weights and measures in dispensing medicines. ${ }^{40}$

Other evidence published at around the same time-i.e., shortly after the enacting of the 1878 Weights and Measures Act-confirms that there were numerous instances of the use of inaccurate apothecaries weights. ${ }^{41}$ There is also similar evidence for the beginning of the century; for instance, when in 1800 the censors of the Royal College of Physicians began to record comments on scales and weights in apothecaries' and in chemists' and druggists' shops, many inadequate items were found. ${ }^{\mathbf{} 2}$

Nevertheless, the general picture was not so black as it may seem. On the last Visitation ever carried out by the Royal College of Physicians, on 2 November 1858, the weights and measures of Schacht \& Co. were 'exceedingly good'. Likewise, an examination of the scales and weights in the Wellcome Collections indicates that the general situation was probably not so bad as might be imagined. Although only about 50 per cent of weights in the Wellcome Collections have an accuracy within the narrow limits laid down following the $1878 \mathrm{Act}^{43}$ relatively few have excessive errors such as indicated in footnote 39 .

This is in spite of the rough and ready appearance of the common, irregular,

30 Casual dispensing is perhaps reflected in the interesting makeshift paper 2 grain weight illustrated in fig. 2. Medicine chest booklets were exceedingly common, ranging from a simple list of contents in the chests to treatises on domestic medicine; but all gave careful directions about dosage. One of the earliest, Hugh Smith's The Family Physician (London, 1760), stated that 'with each box of medicine will be a box of scales and weights; each weight marked distinctly, that any person may at once adjust the proper quantity for a dose' ( $(p$. iv). Smith gave a range of three doses (under 7 years, between 7 and 14, and above 14) while the most successful booklet of the nineteenth century-Cox's Companion to the Family Medicine Chest-gave doses for ages under 1, 2, 3, 4, 7, 14 and 20 years and over 21, over 65 and over 80 .

30 About 3 per cent (i.e. c. 60) of the weights in the Collections have an error of 25 per cent or more.

${ }^{10}$ Pharm. J. Trans., 1881-82, 12 (3), 674.

41 For example, The Pharmaceutical Journal and Transactions $(1882-3,13$ (3), 488) reported that 24 shops in one city were examined. In only four instances were all the weights and measures found correct. Of 1,207 weights examined 128 were found too light, 97 were too heavy, and 59 were illegal only in being unstamped.

'a Remarks in the censors' Visitation Books include 'scales not to be depended on to a grain' and 'weights but indifferent'. We are grateful to Mr. L. M. Payne, Librarian, Royal College of Physicians, for permission to consult the Visitation Books.

"The limits used for this assessment are those laid down in The Weights and Measures Inspectors' Vade-Mecum, Hastings, 1910. These are in fact more stringent than those announced in Pharm. J. Trans., 1881-82, 12, 10 . 


\section{Drug Weighing in Britain, c. 1700-1900}

square-shaped drachm and scruple weights (see fig. 1 a-d). Relatively few square weights were elegantly finished with bevelled edges (fig. 1 e-f), with rims (fig. $1 \mathrm{i}-\mathrm{j}$ ), or with engraved denominations (fig. $1 \mathrm{f}$ ), although, in contrast, handsomely produced coin-like and lozenge-shaped weights became increasingly popular. Very large numbers of these latter weights were produced, from 1847 onwards, by the wellknown Birmingham firm of W. \& T. Avery and by many other companies, of which the only one so far identified is another Birmingham firm, Rogers \& Co. (see fig. 5).

It is difficult to say what general influence these elegant, coin-like and lozengeshaped weights had, but, despite the oft-repeated criticism that the embossed surface readily picked up dirt, they soon achieved considerable popularity and successfully competed with the common square weights. (Some 20 per cent of the 1,000 or so English drachm and scruple weights in the Wellcome Collections are of the coin and lozenge types). Soon after their introduction they received favourable notice in an important American textbook: after commenting that most imported weights are 'very faulty' it was stated that 'Within a few years past a description of weights from $3 \mathrm{ij}$ to $\exists$ ss has become common on our market, quite preferable to the German square weights of the same denominations.' 44

This encomium came, as already emphasized, in the absence of verification stamping, an absence amply proven by the Wellcome Collections: out of the 1,000 or so drachm and scruple weights there are only eight possible exceptions (see fig. 3 and accompanying notes).

A survey of about 1,100 grain weights in the Wellcome Collections shows that in spite of the exceptions noted in footnote 26 they are generally more accurate than those of drachm and scruple denomination. This, as has been indicated, is because many grain weights were stamped for use in weighing coins. It is relevant to add that coin weights of larger denominations were probably used occasionally for dispensing. The Wellcome Collection of boxes of dispensing scales and weights includes many examples and it would have been convenient, as Thomas Henry pointed out in 1775, to use certain pennyweights for dispensing: for example, 5 pennyweights is equivalent to 2 drachms (see fig. 8 and notes). It is perhaps not inappropriate to mention that members of the medical and pharmaceutical professions, like other members of the community, were greatly concerned with the weights of gold coins they were offered in payment. This is emphasized pungently in an anonymous caricature, 'Dr. Gallipot with his wig of knowledge' (1774) where the physician is weighing his fee in front of his sick patient. ${ }^{45}$ It is also of interest that a collapsable money scale in the Wellcome Collections has been graduated to weigh apothecaries drachms and scruples.

The most inaccurate weights in the Wellcome Collections are, perhaps not surprisingly, the nested troy weights of denominations $\frac{1}{2} \mathrm{oz}$. to 8 or $16 \mathrm{oz}$. As nineteenthcentury critics often remarked, such weights were specially subject to wear and tear and, what is more, rarely stamped and inspected. In 1869, Henry Skinner, a manufacturer of scales and weights, commented that: 'if we get a set of Troy weights from a chemist, or jeweller, or pawn broker, they are generally very light . . . [and]

4 E. Parrish, An Introduction to Practical Pharmacy, Philadelphia, 1856, p. 27.

is See illustration in M. D. George, Hogarth to Cruikshank: Social Change in Graphic Satire, London, 1967, p. 92. 


\section{J. K. Crellin and J. R. Scott}

I never had a set stamped in my recollection.' 46

However, the potential dangers from inaccurate troy weights need not be overestimated for, as has been stated, avoirdupois weights were commonly used in place of the large troy weights. Examples of nested troy weights are illustrated in fig. 7 (see accompanying notes about the occasional inadequate inscriptions and the possibility of confusing troy and avoirdupois weights).

\section{SCALES}

Even the most accurate weights could, of course, have had their effect lessened by inaccurate scales. In 1881, Redwood remarked in disgust that 'the same old system of using a pair of hand scales which are roughly taken out of a box and roughly thrown back again each time they are used, which prevailed a century or two ago in the days when Mithridate and Venice treacle were looked upon as potent medicines, still prevails and is apparently considered equal to the requirements of modern pharmacy.'47

There is no doubt that the most popular scales in eighteenth/nineteenth-century dispensing were equal-arm hand scales rather than pillar or bench models; with them, it was stated, the 'processes of weighing [can be] conducted much more expeditiously' ${ }^{48}$ References to hand scales in this study does not cover the small steelyards occasionally used in dispensing. ${ }^{49}$

English equal-arm hand scales-which are discussed more fully in the appendixcan be divided into those which have a box-end beam (that is where the pivot for the suspension of the pan strings is protected) and those which have a swan-neck beam end, the suspension point being open. The box-end beam became popular during the eighteenth century and it was undoubtedly considered superior to the swan-neck beam end, provided that the pins from which the pans were suspended were of hard metal; the user could test this for himself. The nineteenth-century illustrations of pharmaceutical scales invariably show box-ends ${ }^{50}$ and in 1824 the author of An Explanatory Dictionary of the Apparatus and Instruments employed in the various operations of Philosophical and Experimental Chemistry ${ }^{51}$ stated that the 'best kind of hand scales are those which are furnished with a box-end . . . and have a ring or sight hole at the upper extremity of the fork which supports the beam.'

Despite the high regard for the box-end beam it seems that swan-neck beam scales were more commonly used, a situation even applying to diamond and coin scales as

\footnotetext{
${ }^{4}$ Third Report of the Commissioners Appointed to Enquire into the Condition of the Exchequer (now Board of Trade) Standards: On the Abolition of Troy Weight, London, 1870, p. 21.

17 Redwood, op. cit., (footnote 40).

48 F. Mohr, and T. Redwood, Practical Pharmacy, London, 1848, p. 265.

40 There is no example in the Wellcome Collections of a steelyard designed for dispensing; the only recorded example appears to be that mentioned by Kisch, op. cit. (footnote 4), p. 66. That similar steelyards achieved some popularity in the late nineteenth to early twentieth century can be seen from contemporary sources (e.g., Pharm. J., 1907, 24 (4), 51, 71).

${ }^{50} \mathrm{See}$, for example, footnote 48 , p. 270. A rather delightful picture of box-end hand scales is shown in an interior view of the famous Plough Court Pharmacy depicted in J. Hatton, "An Historic Pharmacy', Supplement to Chemist and Druggist, 28 January 1893. W. Whitla's Elements of Pharmacy, Materia Medica, and Therapeutics, London, 1882, p. 4, is exceptional in showing a swan-neck beam.

$s 1$ London, p. 45.
} 


\section{Drug Weighing in Britain, c. 1700-1900}

evidenced by those in the Wellcome Collections. The reason for this unexpected situation is not entirely clear, but the comparative cheapness of the swan-neck variety must have been an important factor. ${ }^{52}$ Furthermore the large Wellcome Collections provide no evidence that the swan-neck scales were generally less accurate unless deliberately made false, ${ }^{53}$ and it is probable that scales were generally more satisfactory than weights. ${ }^{54}$

Despite the popularity of hand scales, bench scales had long been in use before they began to replace hand scales during the last two decades of the nineteenth century. In 1831 they received strong recommendation for use in dispensing, ${ }^{55}$ and examples of the types which were in common use are illustrated in fig. 9. Not illustrated are the more accurate bench scales, found in first-class establishments, designed for measuring specific gravities or for use in analysis. These were generally used with decimal grain weights of denominations of $1,000,500,400,300,200$ and 100 grains, weights which can occasionally be found in boxes of dispensing scales. ${ }^{56}$ Most of the nineteenth-century bench dispensing scales in the Wellcome Collection show a good degree of accuracy, as undoubtedly did scales for analytical purposes. ${ }^{57}$ Nevertheless the real superiority of bench over hand scales only came with those having continuous knife edges of agate, a type which gradually came into general use during the first few decades of this century. ${ }^{58}$

In contrast to dispensing and analytical scales were scales used for weighing large quantities of drugs and for general retail transactions. Such scales were not always designed specifically for pharmaceutical purposes (for an exception, see note on fig. 9a) and though equal-arm beams were no doubt generally employed, the possibility that steelyards, bismars, and spring balances were sometimes used must remain. The extensive Wellcome Collections of these large weighing instruments-some of which are on view in the exhibition in the Chapter House, Southwark Cathedral-

\footnotetext{
"2 See, for instance, prices in A Catalogue of Goods Manufactured by James Arnold, London, 1852 , p. 23 , whose scales and weights were 'warranted of the best London manufacture'.

${ }^{58}$ This has been ascertained by the prescribed test for beams, that they attain a perfectly horizontal position on removal of the pans (cf. footnote 71).

s4 Scales, of course, were not always kept in a suitable condition. S. F. Gray (The Elements of Pharmacy, London, 1823, p. 17) remarked that the state of the common apothecaries' grain scales is generally 'a disgrace to their shops', a remark in keeping with comments by the censors of the Royal College of Physicians in their Visitation Reports (see p. 58.) There were frequent injunctions to keep scales away from fumes, but in the absence of adequate inspection-and judging from some of the Wellcome scales-it seems clear that this warning was not always heeded.

${ }^{65}$ R. J. Kane, Elements of Practical Pharmacy, Dublin, 1831, p. 4. An interesting illustration of bench scales being used at around this time in a Philadelphia pharmacy is in G. B. Griffenhagen's 'The pharmacy in history', J. Int. Coll. Surg., 1958, 29, 789-803.

so Mohr and Redwood, op. cit., (footnote 48), pp. 266-67, discuss these more accurate scales. They illustrate an example from De Grave \& Co., which apparently has compartments for the decimal grain weights of the type illustrated in fig. 3. Such weights are found occasionally in dispensing boxes suggesting the possibility that such weights were 'borrowed' for use in dispensing.

87 For some discussion of nineteenth-century English analytical scales see J. T. Stock, J. Chem. $E d ., 1968,45,254-57$. There appears to be no detailed study of eighteenth-century balances, but for useful information see references under footnote 63 . It may be a relevant comment on the accuracy of eighteenth-century weights that William Lewis, for instance, prepared his own. (See his Commercium Philosophico-Technicum, London, 1763, p. 544).

s8 The use of balances with the continuous agate knife-edge was promoted by more stringent requirements for balances as a result of regulations introduced in 1907.
} 


\section{J. K. Crellin and J. R. Scott}

are summarized in footnote 59.

\section{FACTORS FAVOURING THE USE OF ACCURATE SCALES AND WEIGHTS}

If then the Wellcome Collections indicate that, despite the absence of adequate verification and inspection schemes for most of the eighteenth and nineteenth centuries, large numbers of scales and weights were sufficiently accurate, what were the factors that led to the production of scales and weights of satisfactory accuracy?

Undoubtedly one of the most important factors was the influence of first-class manufacturers. The following question and answer is recorded in the Third Report of the Royal Commission on the Exchequer Standards: 'Have you known instances of tradesmen suffering or alleging that they suffer from the negligence of their scalemakers?-I have known many instances of their suffering when they have employed a tramping person, falsely called a scale maker, but not when they have employed a respectable scale maker and those classes of persons who have made the complaint are those that would employ trampers.'

The story of the making of scales and weights has many ramifications, in part because there was no English guild specially connected with scale or weight making -blacksmiths, ironmongers, founders, pewterers, and plumbers all had a share in the trade. Skilled craftsmen, such as clock makers, spectacle makers, and scientific instrument makers, as well as the specialist scale makers who became more and more prominent during the eighteenth century, ${ }^{61}$ all play a notable part. Clock makers, especially in Lancashire, were particularly well known as makers of automatic money scales ${ }^{62}$ and scientific instrument makers made highly accurate scales such as those used by Lavoisier. ${ }^{63}$ However, at least some instrument makers were concerned with the commercial production of the small hand scales relevant to this study; the Wellcome Collections contain, for instance, six late seventeenth-early

69 The Collections contain some 60 English and Continental eighteenth/nineteenth-century wooden and metal steelyards, and slightly fewer equal-arm beam scales. Additionally, there are more than 50 dotchins such as the one illustrated in Chinese Medicine, an Exhibition illustrating the Traditional System of Medicine of the Chinese People (The Wellcome Historical Medical Museum and Library, 1966).

Of special interest is the small collection of bismars, eleven of which are of the type associated with the Scottish northern islands, and two with weighing silk. Dates on these bismars are 1754, $1766,1770,1785$ and 1795 . One undated example has what appears to be a verification stamp, a crown surmounting GR/III. (Other examples of bismars with this stamp, such as in the Science Museum and the Avery Historical Museum, are known).

The Wellcome Collections also include a range of eighteenth/nineteenth-century spring balances of the Salter, mancur, and triangular types.

Op. cit., (footnote 46), p. 21 .

-1 A study of the makers of scales deserves attention. Of interest are R. Campbell's comments in The London Tradesman (London, 1747, p. 327), under the heading 'Beam and Scale Makers'; 'This is a Tradesman compounded of the Smith and Brazier, the Smith makes the Beams, which is the nicest Part of the Branch; and the Brazier the small scales; which are adjusted to the Beam; they sell and make weights of all Sorts, and the few that keep Shops of them make a very good Appearance.'

'2 The role of clockmakers requires fuller study. There is some relevant information in $T$. Sheppard, and J. F. Musham, Money Scales and Weights, London, 1924, pp. 28-29 et seq. The Wellcome Collection of 73 collapsible money scales is not discussed in this publication.

es See, for instance, M. Daumas, Les Instruments scientifiques aux XVII et XVIII Siecles, Paris, 1953, pp. 290-98; and Lavoisier Théoricien et Expérimentateur, Paris, 1955.

More information on eighteenth-century scales can be found in, for example, W. Nicholson's A Dictionary of Practical and Theoretical Chemistry (London, 1808, balances). 
eighteenth-century balances of Henry Neale, and an eighteenth-century shagreen case of A. Smith. ${ }^{64}$

Of the items in the Wellcome Collections bearing labels or initials (a stencilled list of these is available on request) some of the most noteworthy deserving mention are those which point to the influence of a first-class manufacturer such as W. \&. T Avery, Young \& Son, and De Grave \& Co. The particular influence of Avery's coin- and lozenge-shaped weights has already been mentioned and it only remains to comment that the Wellcome Collections also contain some well-made Avery scales and those of Avery's predecessor, T. Beach. ${ }^{65}$ The Wellcome items of Young \& Son ${ }^{66}$ comprise eleven boxes of dispensing scales and weights of which five are superbly-made mahogany boxes (see fig. 10d). Each of these mahogany boxes contains a wood block for holding drachm and scruple apothecaries weights, which are themselves unusual in being the only knobbed examples of apothecaries weights in the Collections. Grain weights were kept in a special compartment with a hinged, brass cover finely engraved with Young's name and address. The scales, too, are exceptionally well-made; they have box-end beams and three have silver pans. ${ }^{67}$ There is much contemporary evidence that Young \& Son were among the leading scale-

\begin{abstract}
a Henry Neale is recorded by E. G. R. Taylor (The Mathematical Practitioners of Tudor and Stuart England, Cambridge, 1954, p. 282) to have flourished at the end of the seventeenth century and to have been renowned as a maker of delicate bullion scales. The Wellcome Collections include four small, solid pearwood boxes-with carved-out compartments for the scales and the weightseach with labels bearing the name and address: Henry Neale at ye End/ of St. Bartholomew Lane near/ the Royal Exchange London. Above the address is the Royal Coat of Arms, to the left the blindfolded figure of Justice, and to the right a very rare dance of death motif of a skeleton looking over the shoulder of a woman holding scales. (On two of the boxes the labels are trimmed to show only the name and address, and the Royal Arms). No weights are present in the boxes but the four scales (beam lengths between 7.5 and $9.2 \mathrm{cms}$., and pan diameters between 3.3 and $3.8 \mathrm{cms}$.) all have the initials $\mathrm{HN}$, which are separated by a hammer(?), in the centre of each pan. The scales were almost certainly made for weighing coins, though it is of interest that identical ones (also monogrammed) occur in a mahogany box containing apothecaries weights. The latter box is part of the contents of a medicine chest, unusual in that it appears to have been used by a medical practitioner for dispensing purposes whereas most medicine chests were used by a family in the home.

The sixth pair of Wellcome scales with the Neale monogram is in a mahogany box which contains two other scales, and the label: 'Wenborn,/ Scale, Weight, \& Steelyard/ Manufactory,/ 190 High Holborn,/ from Youngs/ Scale Makers to His Majesty./ Scales and Weights repaired and adjusted by the Quarter or Year'.

The Wellcome Collections also contain 22 other examples of solid pearwood boxes decorated with tool markings similar to those on the Neale boxes. These were all intended for weighing coins though two contain apothecaries weights. For details of similar examples see T. Sheppard and J. F. Musham op. cit., (footnote 62). Also illustrated in O. Evan-Thomas', Domestic Utensils of Wood, London,
\end{abstract} 1932 , plate 67.

is The Collections have two boxes of coin scales (for counting-house or shop rather than pocket use) with the labels of $\mathbf{T}$. Beach \& Son. These eighteenth/nineteenth-century boxes are elegantly lined with fabric and the beams, with box-ends, are elegantly made (a similar box has been illustrated by L. Sanders, A Short History of Weighing, Birmingham, 1947, fig. 18). It is interesting that the fulcrum of one beam is covered with metal plates, a characteristic which, according to $W$. Nicholson (op. cit. footnote 63), was typical of scales made in 'the country' and not in London. Relatively few Wellcome scales have this covering plate which is illustrated in fig. $10 \mathrm{~b}$.

- This firm commenced in 1777 and is still in business as Young, Son, \& Marlow Ltd. but unfortunately no business records survive. (We are grateful to Mr. W. J. Marlow for this information.) One of the labels on the Young boxes reads 'Sewell \& Young/ Bear Street/ Leicester Square/ London/, Make \& Sell all Sorts of Scales, Weights \& Steelyards/ Wholesale \& Retail/ for Home Trade \& Exportation', a label used when the firm traded under that name during the last years of the eighteenth century. The scales in the box have box-end beams.

or The dates from the hallmarks on the silver pans are for 1814, 1816 and 1821. The Wellcome Collections include seven other scales with silver pans, all from the first half of the nineteenth century. 


\section{J. K. Crellin and J. R. Scott}

makers during the nineteenth century, as were De Grave $\&$ Co. ${ }^{68}$ The De Grave material in the Wellcome Collections is excellent though there is nothing of the calibre of that of Young. Nevertheless the well-constructed mahogany box, with swan-neck beam scales and glass pans, which was owned by Joseph Lister, deserves mention.

The labels on many of the boxes, such as those of Young's (fig. 10d), bear statements about repairs: for instance, 'Shopkeepers Scales kept in Repair by the Year'. Periodic inspections by scale and weight makers, so long as they were conscientiously performed, were no doubt another important means for maintaining accurate scales and weights in the absence of an efficient verification scheme. ${ }^{69}$

This particularly applied to hospitals where even the limited verification scheme did not apply. It is particularly interesting, therefore, that Thomas Williams charged Guy’s Hospital $£ 210$ s. $0 d$. for a year's cleaning in $1807 . .^{70}$ This excluded $3 s .0 d$. for 'six pairs of grain strings' and 10s. $6 d$. for repairing box-end beam scales which would appear to have been the type illustrated in fig. 9a.

It would thus seem that the Guy's Hospital apothecary exercised a high standard of care over his weights and there is no doubt that the conscientiousness of a particular individual was a further important, and frequently decisive, factor in the use of accurate scales and weights. To a much greater extent than nowadays the checking of the accuracy of scales and weights on purchase was necessary and there were certainly many contemporary warnings about the need to do so. ${ }^{71}$ Likewise a correct technique of weighing was necessary and this was emphasized, for instance, by Mohr and Redwood in their Practical Pharmacy (1848). ${ }^{\mathbf{7 2}}$

Such warnings over apparatus and techniques were important, but undoubtedly not always effective at a time when a conscience was not enough to sustain standards throughout the entire, somewhat disparate, professions of medicine and pharmacy. ${ }^{73}$ As has already been indicated, this is clearly reflected in the Visitation Reports by the censors of the Royal College of Physicians and in reports by Weights and Measures Inspectors following the 1878 Act. ${ }^{74}$ Though there seems to have been at least some inspection of chemists and druggists' shops prior to the $1878 \mathrm{Act}$, presumably for

\footnotetext{
${ }^{68}$ The firm of De Grave was founded during the last quarter of the seventeenth century and remained an independent company until 1920 . We are grateful to Mr. J. Rock Cooper for helping us with this information. Mr. Rock Cooper also informs us that there are no surviving records except an invoice of Mary De Grave 'widow and successor to the late Charles de Grave' for 1803-1804. It bills a Mr. Everingham for repairs, and for cleaning and adjusting Beams and Weights (cf. p. 56).

(O) The widespread practice of periodic inspection by makers is indicated, for example, in the Report of the 1835 Select Committee on the Weights and Measures Act; together with the Minutes of Evidence, p. 39. J. Perry, The Story of Standards, New York, 1955, p. 38, however, notes a statement suggesting that such inspections often left much to be desired.

${ }_{70}$ Bill in Guy's Hospital records.

71 To give but one example A. T. Thomson, The London Dispensatory, London, 1811, p. Ixxvi, stressed that a 'good beam should remain in equilibrium, both by itself, and when the scales are suspended indifferently to either extremity'. Thomson also stresses the importance of keeping scales away from laboratory fumes.

${ }_{72}$ Mohr and Redwood, op.cit. (footnote 48), p. 269.

${ }^{73}$ There is much published evidence for this; see, for example, part 1 of this series, Med. Hist., 1967, 11, 215-27.

74 See, for instance, Report by the Board of Trade on their Proceedings and Business under the Weights and Measures Act 1878, 1882, p. 5. See also footnote 41 .
} 


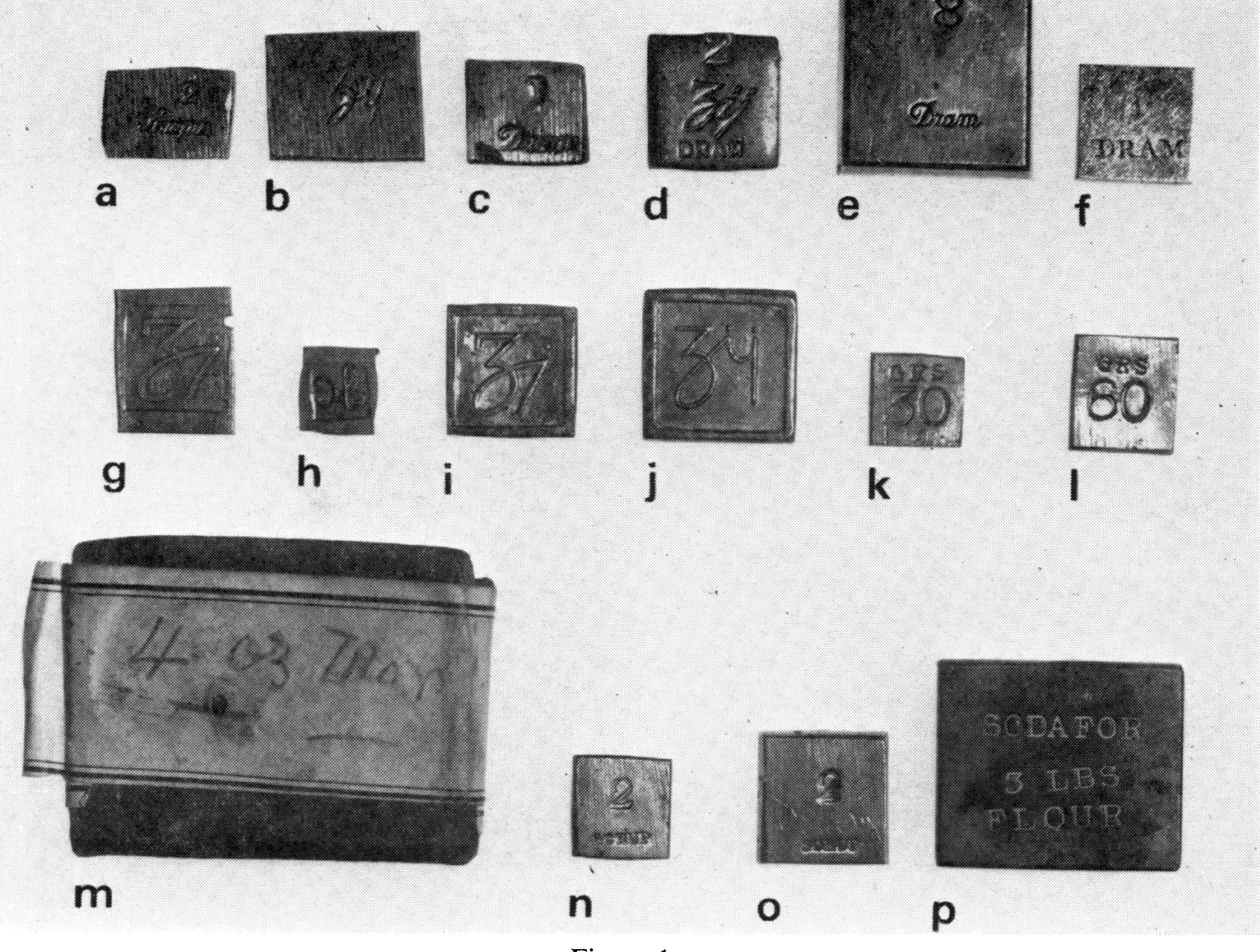

Figure 1.

Square pharmaceutical weights.

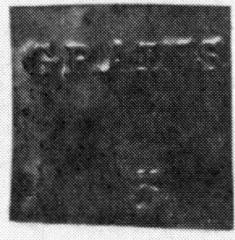

a

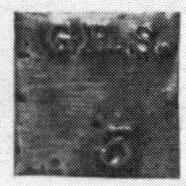

b

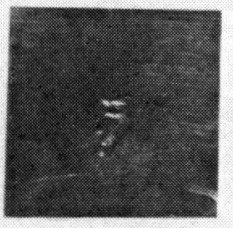

C

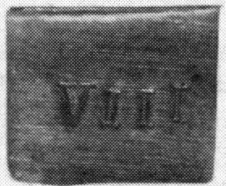

d

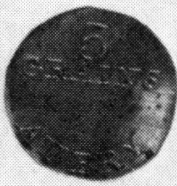

e

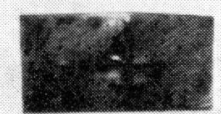

$f$

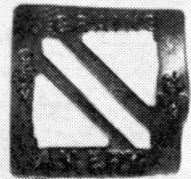

g

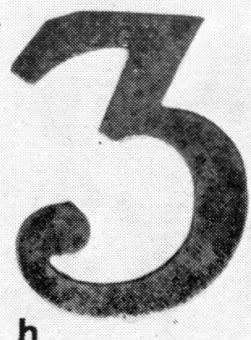

h

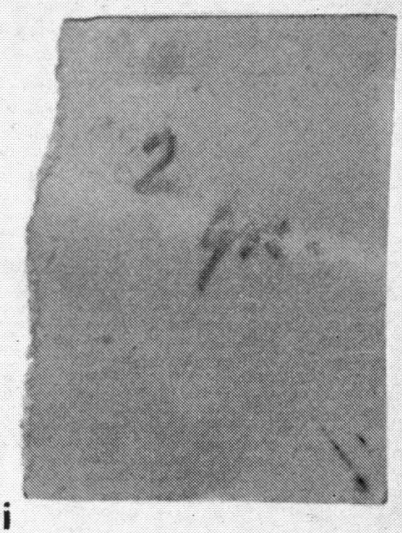

https://doi.org/10.1017/50025727300013946 Published online by Cambridge Figure $\begin{gathered}\text { Cigurety Press } \\ \text { Grain weights (cf. also figure 4). }\end{gathered}$ 


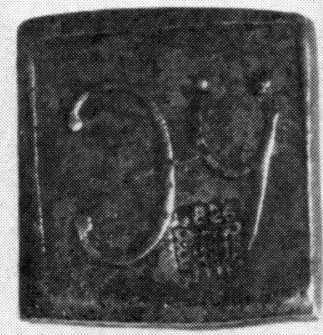

a

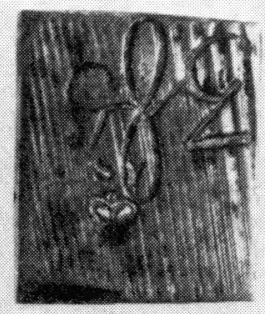

C

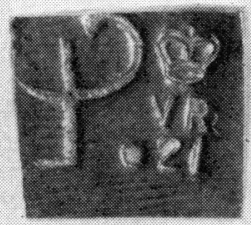

e

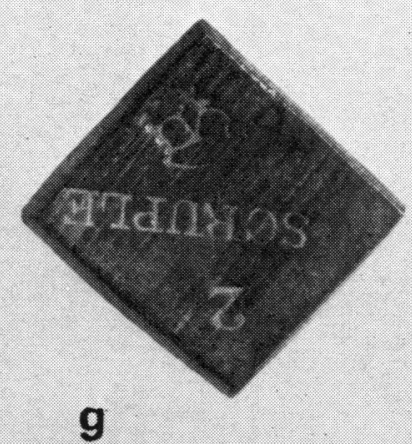

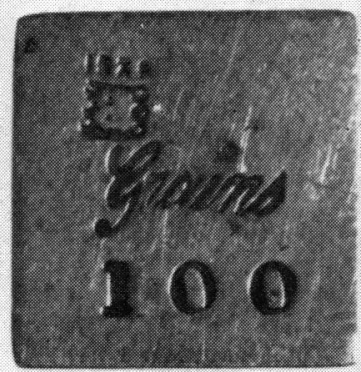

b

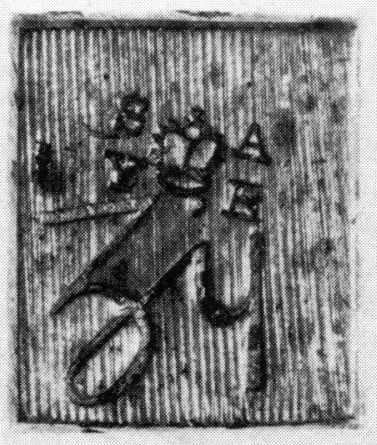

d

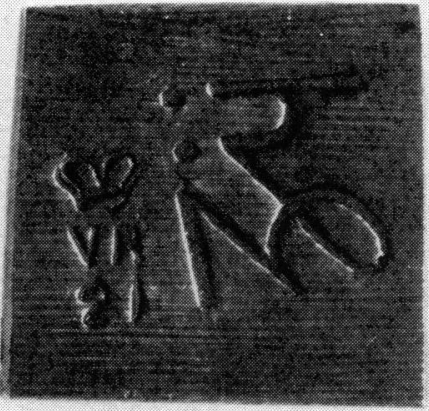

f

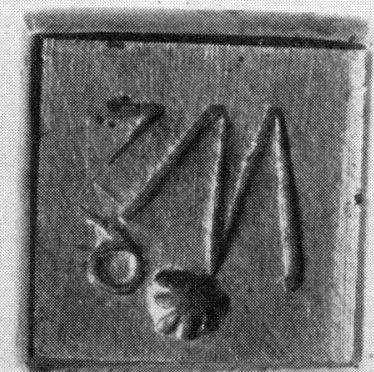

h 


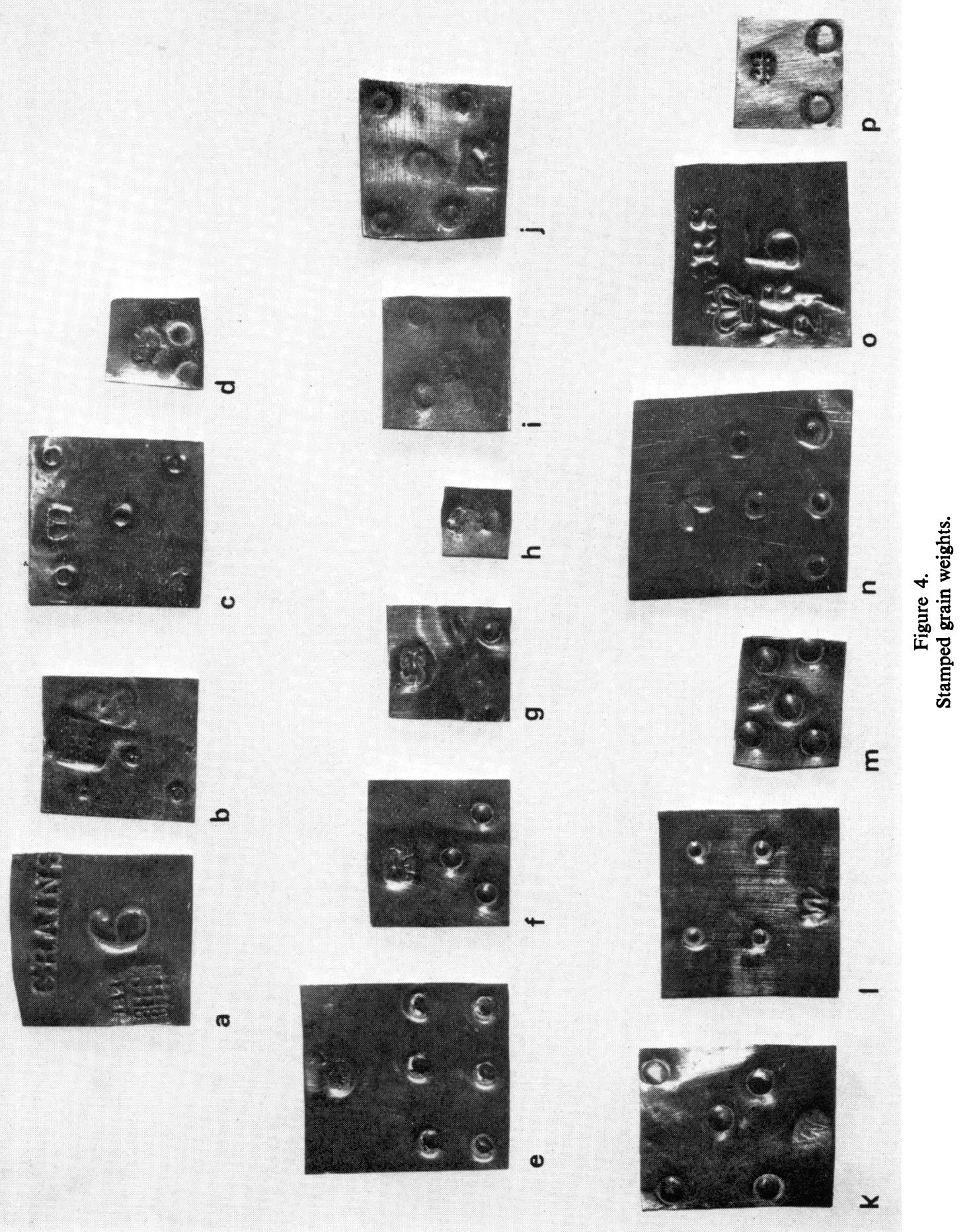




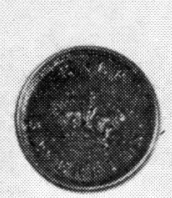

a

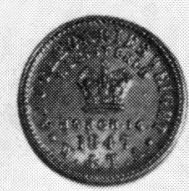

b

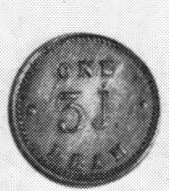

C

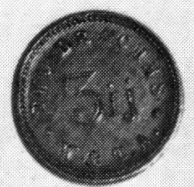

d

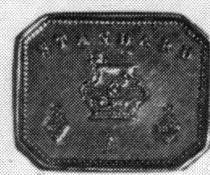

e

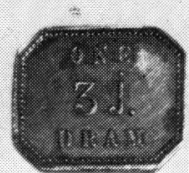

f
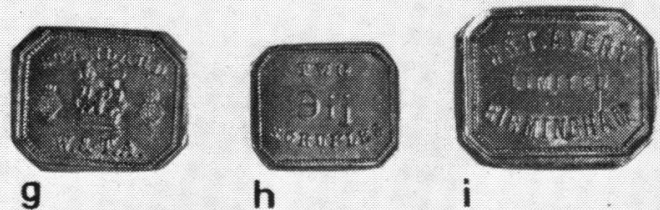

h

i
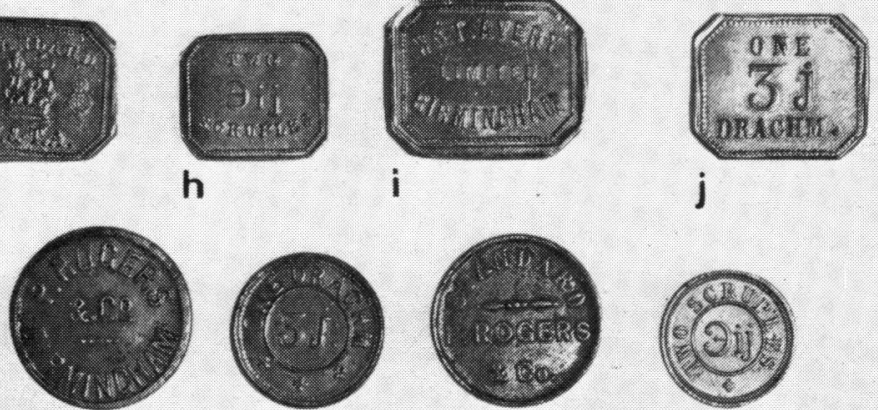

k
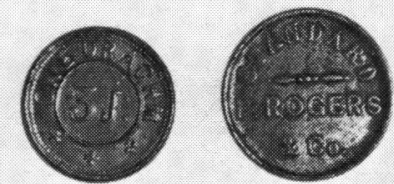

m

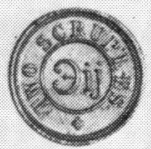

n

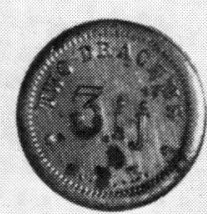

o
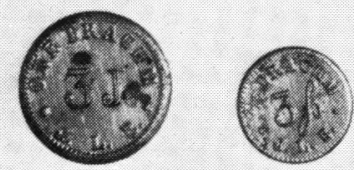

p

9

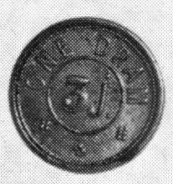

r

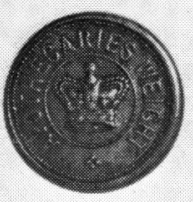

s

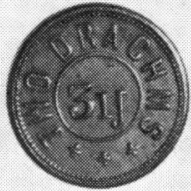

t

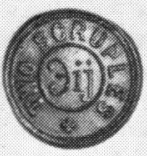

u

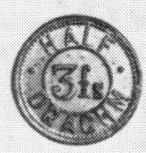

v

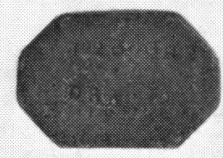

w
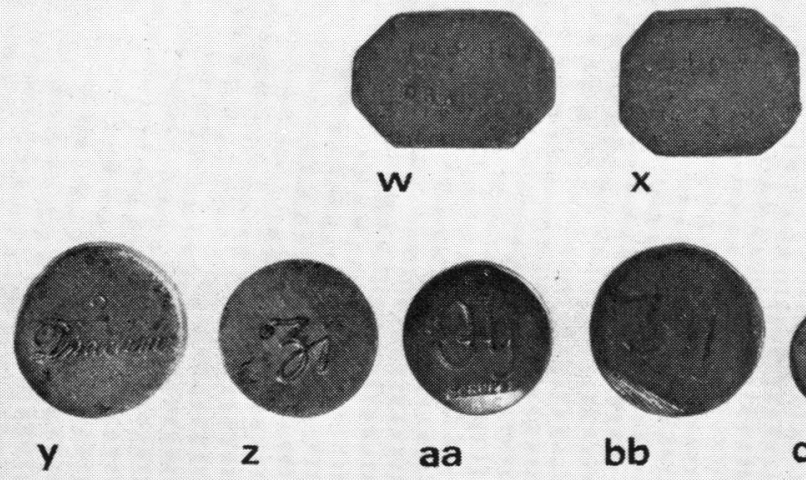

$z$

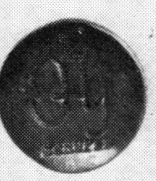

aa
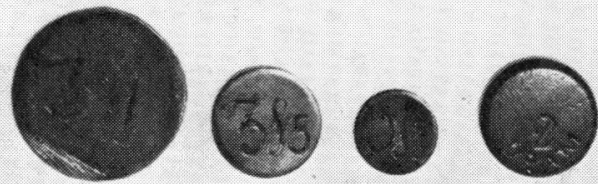

bb

cc

dd

ee

Figure 5.

Coin- and lozenge-shaped drachm and scruple weights. 


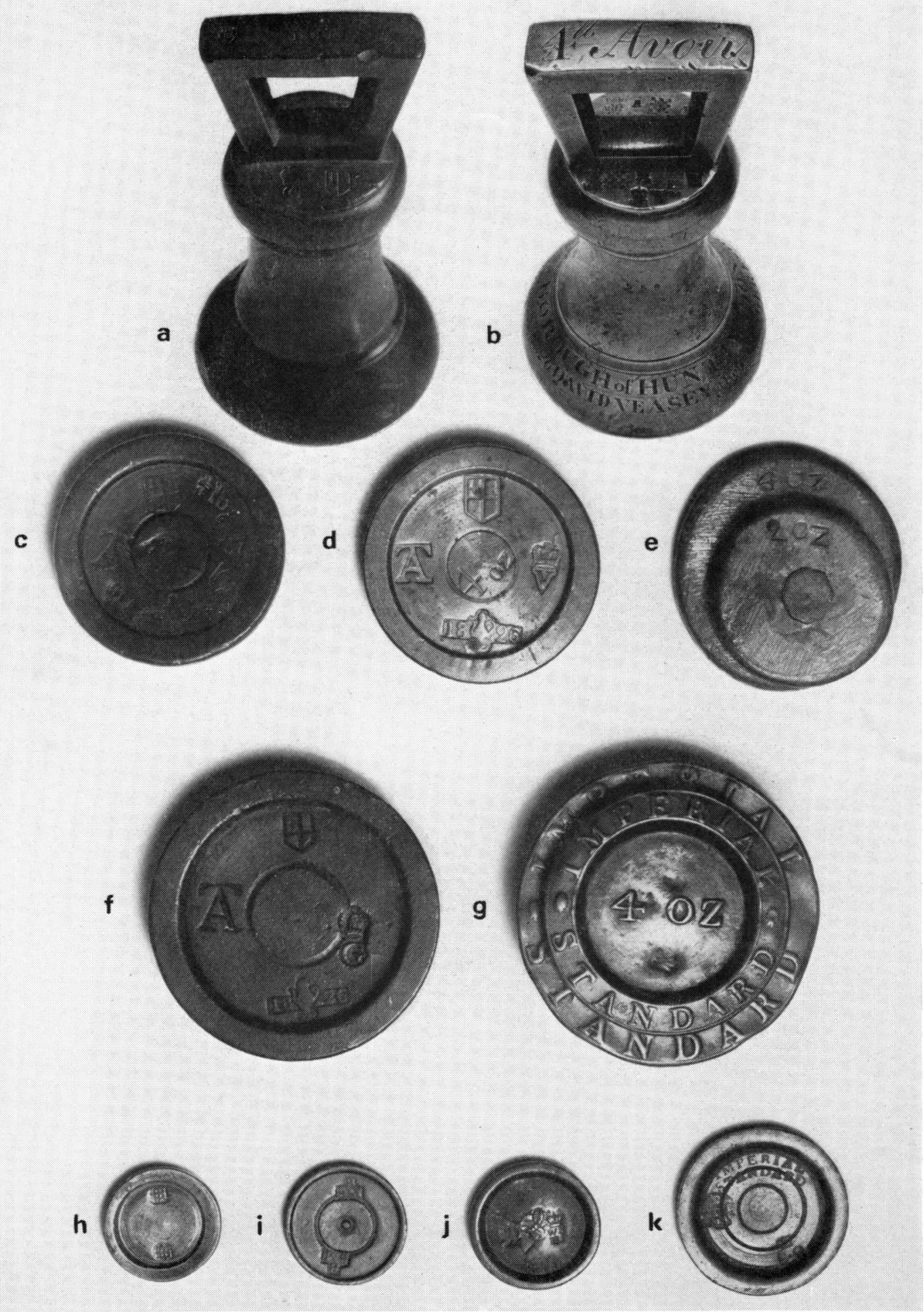

Figure 6.

Avoirdupois weights 


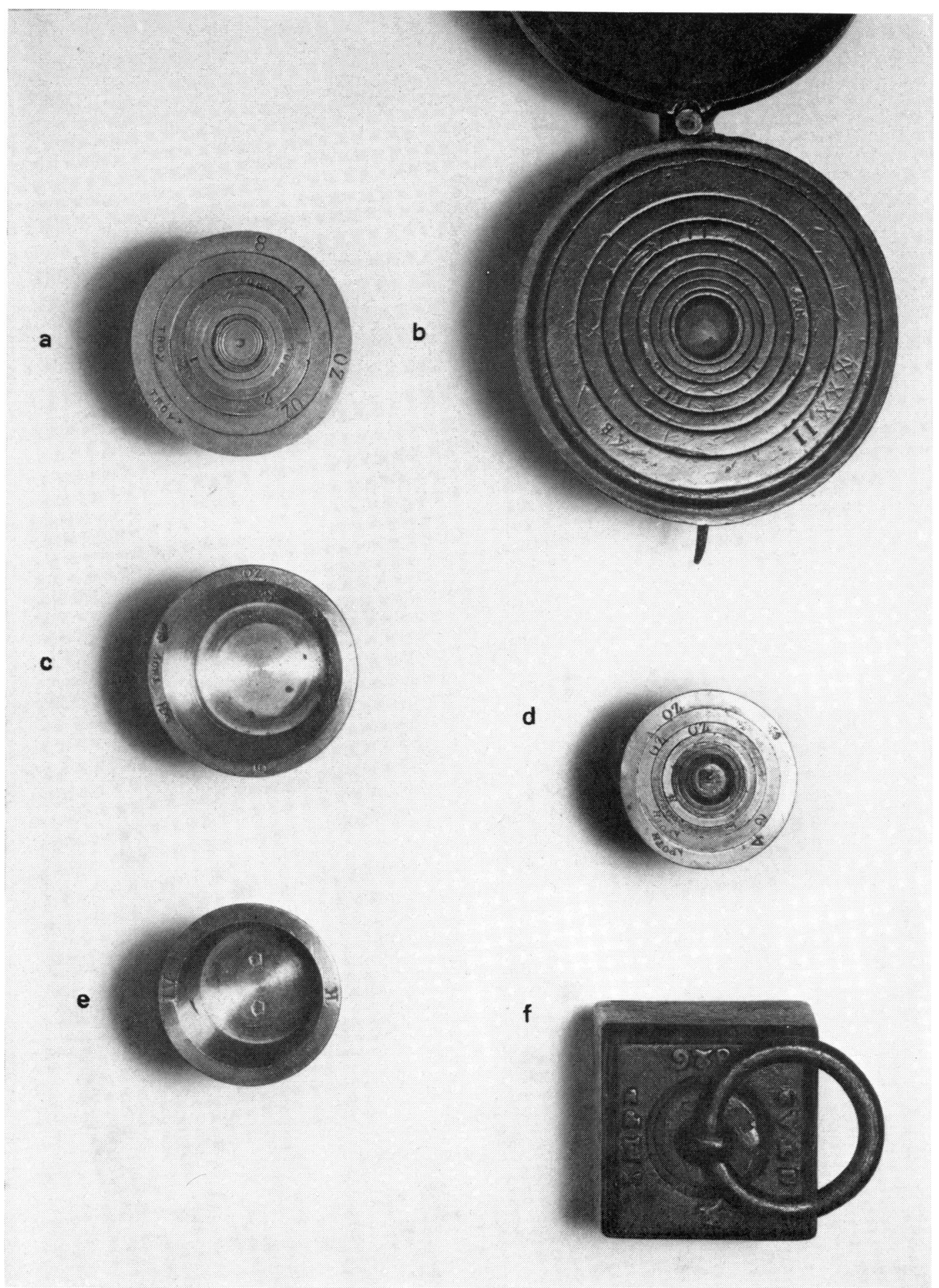

Figure 7.

Troy and avoirdupois weights (cf. also figure 6). 


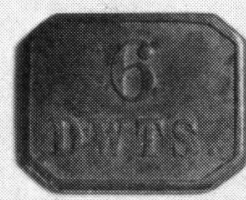

a

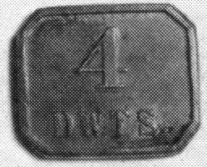

b

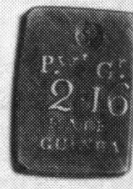

c

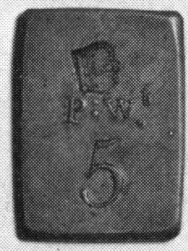

d

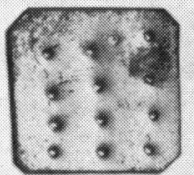

e

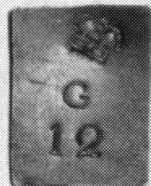

f

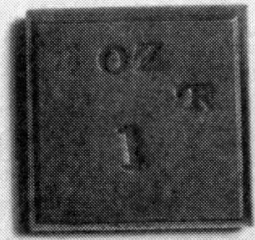

g

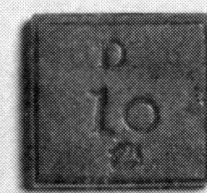

h

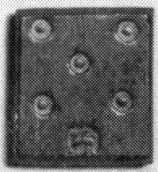

i

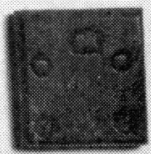

j

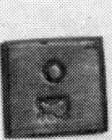

k

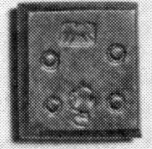

I

Figure 8.

Troy weights.
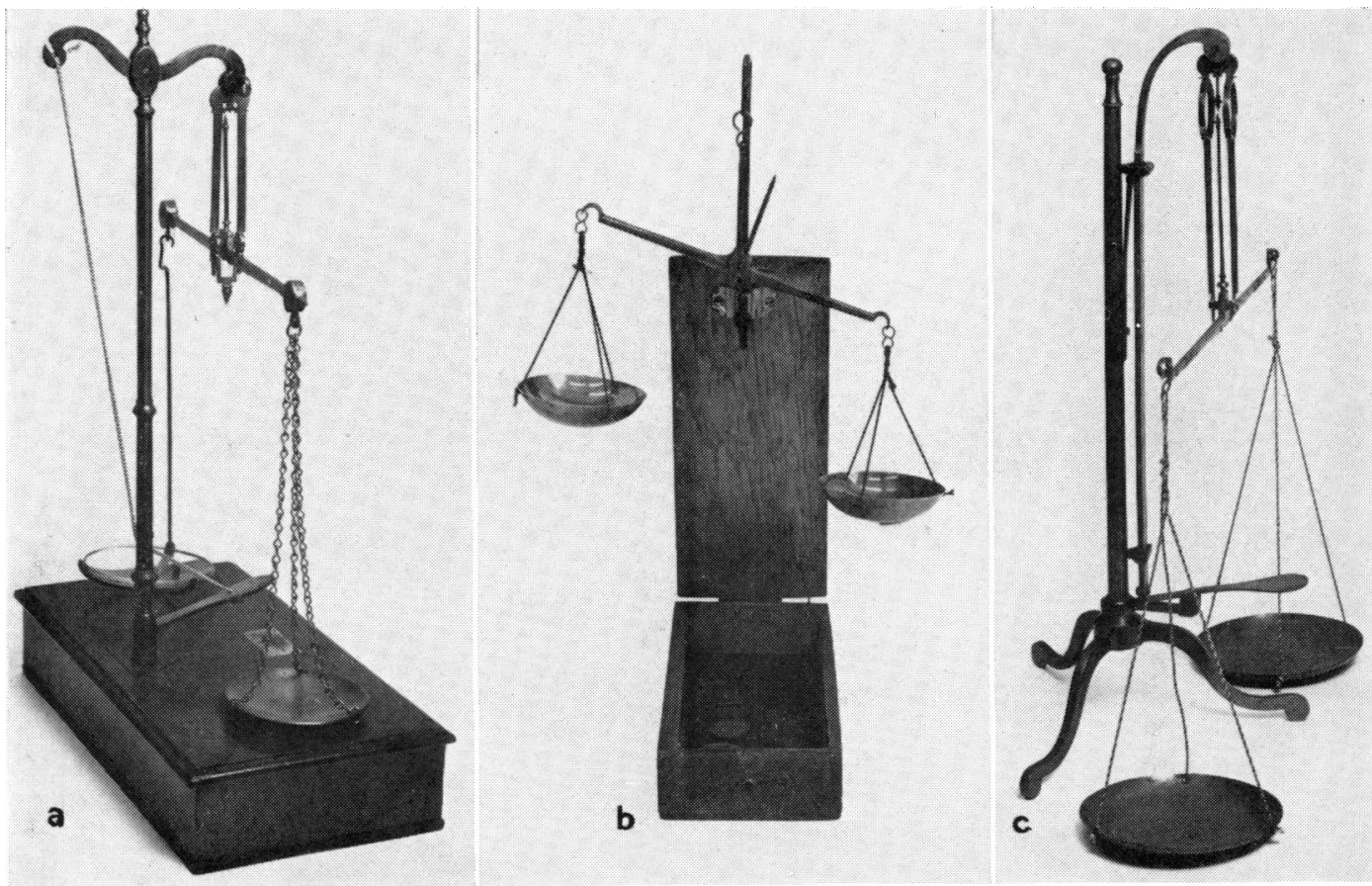

Figure 9.

Bench dispensing scales 

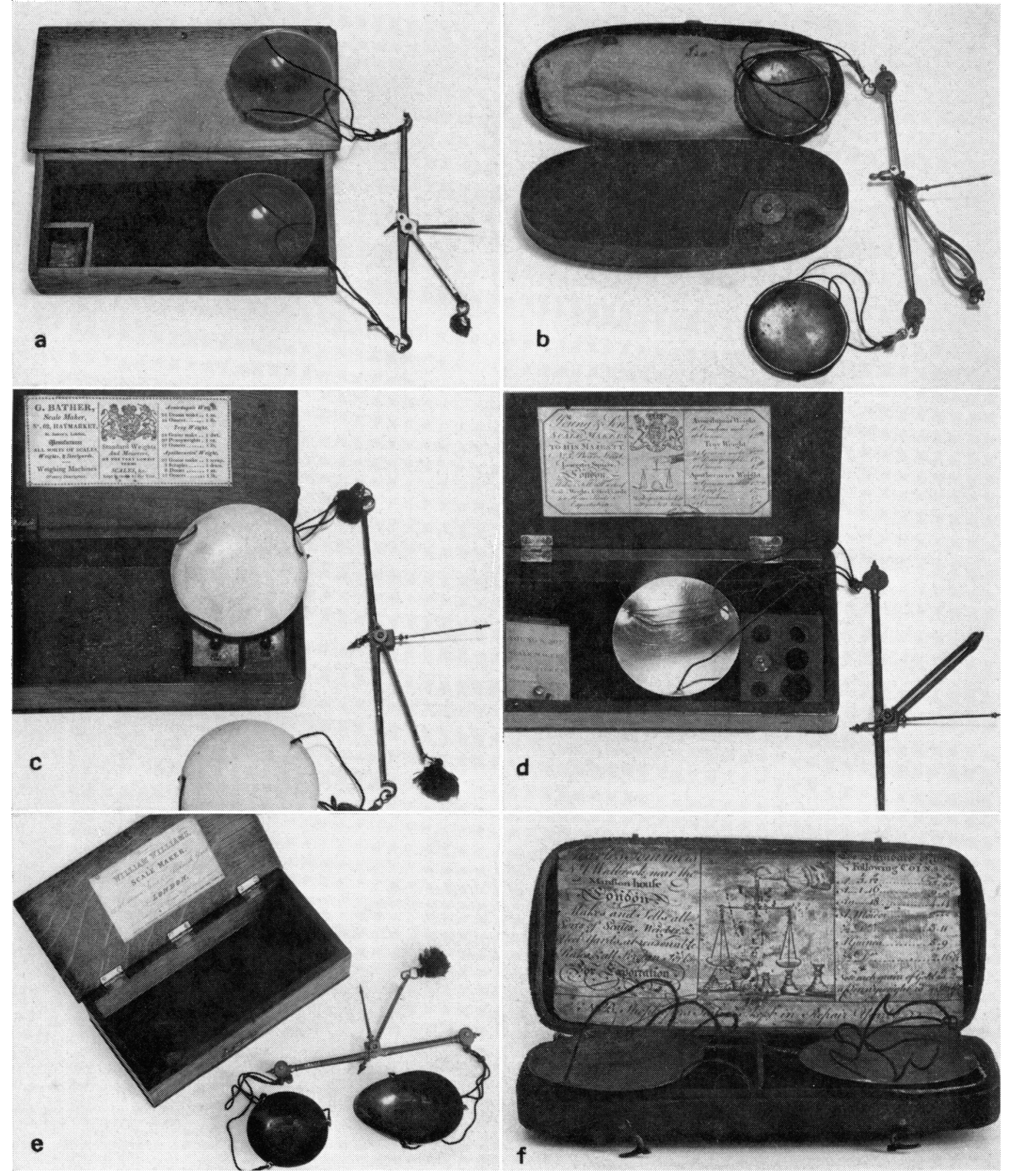

Figure 10.

Boxes of scales and weights. 


\section{Drug Weighing in Britain, c. 1700-1900}

\section{NOTES ON FIGURES}

Figure 1. Square pharmaceutical weights

These 18th to 19th-century square weights range from the common type (a-d), which seem to be roughly made, to elegant weights with bevelled edges (e-f), and with rims (i-j). The appearance of some of the roughly made weights certainly substantiates Mohr \& Redwood's 1848 comment that many small weights 'appear to be frequently made in a very careless and imperfect manner' (Practical Pharmacy, London, 1848, p. 270).

Also illustrated are a 'home-made' lead weight $(\mathrm{m})$ and a two-drachm weight labelled 2 SCRUP (o), both testifying to the absence of a verification scheme.

a. Two-scruple weight. Reverse in style of $b$.

b. Two-drachm weight. Reverse as a.

c. One-drachm weight. Reverse as a.

d. Two-drachm weight unusual in that denominations are inscribed in both word and symbol on the same side, an advantage over weights only marked with a symbol. Reverse blank.

e. Eight-drachm (i.e., one ounce) weight, elegantly finished with bevelled edges. Reverse identical. Eight-drachm square weights are rare, 'apothecaries' ounce weights generally being part of a nested set of troy weights (see fig. 7).

f. One-drachm silver gilt weight, from an English medicine chest of c. 1780. An unusual feature is that the denomination is engraved on the weight.

Weights $g-j$ are examples of rimmed weights of varying quality; the appearance of $g-h$, for example, leaves elegance much to be desired.

g. One-drachm weight which has been adjusted by the removal of a small piece of the weight. Reverse inscribed 60/GRAINS.

h. Half-scruple weight. Reverse inscribed 10/GRAINS.

i. One-drachm weight. Reverse inscribed 1/DRACHM.

j. Two-drachm weight. Reverse inscribed 2/DRACHMS.

k.-1. Two weights unusual in being inscribed only in grains (30 and 60 grs.). Reverse of each identical

m. Strip of folded lead covered with paper label inscribed ' $4 \mathrm{oz}$. TROY'.

n.- - . A two-scruple and a two-drachm weight, the latter inscribed ' 2 SCRUP'. An example of the more serious errors among weights in the Wellcome Collections.

p. A 'cooking' weight found among the weights in a 19th-century medicine chest.

Figure 2. Grain weights (cf. also fig. 4)

The majority of 18 th to 19 th-century grain weights have their denominations marked by punch marks as illustrated in figure 4 . In this figure comparatively rare weights with denominations denoted by numbers are shown. Two weights ( $\mathrm{g}$ and $\mathrm{h}$ ) are of considerable interest in that they were introduced in order to overcome the dangers of misreading the denominations of the small weights. Also illustrated ( $f$ and $i)$ are examples of 'home-made' weights possibly reflecting a casual attitude to weighing.

a.-b. Two weights ( 5 and 3 grains) with the denominations marked by numerals, and by word or abbreviation.

c. A five-grain weight marked by number only.

d. An eight-grain weight marked with Roman numerals. Its eight-grain denomination suggests its use for weighing coins or bullion rather than drugs.

e. A five-grain circular weight produced by W. \& T. Avery towards the end of the 19th century.

f. Makeshift two-grain weight, being a four-grain weight cut into two.

g. A six-grain weight produced by W. \& T. Avery. This weight has the post-1878 verification stamp of a crowned monogram VR and the district stamp number 3 (Edinburgh).

h. Three-grain aluminium weight of the type which seems to have become popular in the late 19 th and early 20 th century. The weight bears the crowned monogram GR with the district stamp 30 (London).

i. Makeshift paper two-grain weight (see footnote 38).

Figure 3. Stamped drachm and scruple weights

The rarity of drachm and scruple weights which were stamped before 1878 has been stressed on p. 59. Some possible exceptions are illustrated in this figure.

a. A two-scruple weight with the portcullis stamp of the City of Westminster surmounted by the date 1826. This stamp, however, may have been applied after the 1878 Act as it continued in use after the Act. The 1882 Report by the Board of Trade on their Proceedings and Business under the Weights and Measures Act, 1878, Appendix 3, states that Westminster was then one of the few authorities not to have adopted the uniform verification stamp of a crown over the royal monogram plus the number of the district where the stamp was applied. 


\section{J. K. Crellin and J. R. Scott}

b. A 100-grain weight with the same stamp as on a. Official stamping of such weights was commenced after 1870 (see footnote 7).

c. and d. A half-drachm and a two-drachm weight. Weight c has a stamp of a crown surmounted by the letters SY and weight $d$ a crown with the letters SY on the left hand side and AE to the right. These stamps have been recorded as pre-1878 Surrey stamps, the letters $A$ and $E$ on $d$ being district areas (see Libra, 1966, 5, 24). There are four examples with Surrey stamps in the Collection.

e.-f. A one-scruple and a two-drachm weight with the standardized verification stamp which became widely used after the 1878 Weights and Measures Act. VR indicates Queen Victoria's reign and 21 indicates a London stamp.

g. Two-scruple weight with unidentified crown.

h. A two-drachm weight with star-like mark. This weight, though found in an oak box containing English dispensing scales, is possibly of Continental origin. This is strongly suggested by the similarity of the form of the symbol with those on Continental weights.

Unfortunately the star-like mark has not been identified though it resembles some Dutch marks (see Zevenboom, K.M.C. and Wittop Koning, D.A., Nederlandse Gewichten, Leiden, 1953).

Figure 4. Stamped grain weights

The weights shown in this figure, typical of stamped grain weights in the Collections, illustrate some of the problems that remain to be solved in connection with verification stamps. Weights with the 'lion' stamp (e-j) are generally thought to have been applied by assay offices, especially the Goldsmiths Company of London. However, the variety of stamps indicates that this is not a satisfactory answer. Furthermore, Mr. J. S. Forbes of the Goldsmiths Company has kindly told us that no evidence can be found of the stamping of weights by the Company during the 18th and 19th centuries. Possibilities which remain to be considered are that the stamps were an association of ideas with silver and gold assay marks, or that they were fraudulently added.

Weights $k-n$ and $p$ show a variety of other stamps which have not been identified. Though the weights are from English medicine chests and boxes of dispensing scales and weights, the possibility remains that some may be of Continental origin. Some of the stamps (for example, $k$ ) appear to be monograms and perhaps represent the initials of the maker.

All the weights except a and o are marked with punch marks, each mark indicating one grain. This method of denoting the size of the weight led to criticism that the stamp could be interpreted as a punch mark thus leading to an incorrect reading of the denomination of the weight.

a. Six-grain weight with the portcullis stamp of Westminster surmounted by the date 1826 . This stamp may well have been applied as a result of the court case noted on page 55, though it is possible that it was added after the 1878 Weights and Measures Act (see note with figure 3a).

b. Three-grain weight with the portcullis stamp of Westminster without a date (cf.a). The weight also has a partly obliterated lion stamp similar to that on $\mathbf{g}$.

c.-d. Five-grain and two-grain weights with crown stamps. These could have been applied by the stamper appointed under the 1774 Act (see p. 55), though only the two-grain weight has the imperial crown.

e.-j. Various weights with 'lion' stamps.

k. Five-grain weight with monogram stamp JW. Possibly maker's initials.

1. Four-grain weight with w-like mark, possibly maker's initial.

m. Five-grain weight with the star-like mark (cf. figure $3 \mathrm{~h}$ ).

n. Six-grain weight with stamp of three leaves.

o. Five-grain weight with post-1878 stamp of the crowned royal monogram (Victoria) and the London district number 21.

p. Two-grain weight stamped with pattern of dots.

Figure 5. Coin- and lozenge-shaped drachm and scruple weights

Weights $b-j$ are examples of the variety of coin- and lozenge-shaped weights issued by W. \& $T$. Avery. The coin-like weights were registered on 16 March 1847 (cf. b) and the lozenge shaped weights in September 1850 (see registration mark on e). Such registration gave protection against production by other manufacturers for three years.

The elegant appearance of these Avery weights-at least those of coin shape-was enhanced when they were sold in red-lined mahogany boxes of which there are two examples in the Wellcome Collections. An important feature of the weights is that their denomination is denoted both by symbol and by word.

a. Coin weight for half sovereign inscribed on reverse, 'W. \& T. Avery.' 'Standard'. 'Prototype' of apothecaries weights $b-d$.

b. Two-drachm weight. Reverse in style of c.

c. One-drachm weight. Reverse as b.

d. Two-drachm weight. Reverse identical.

e. Two-drachm weight. Compare initial $\mathbf{A}$ with designations on $\mathbf{g}$ and $\mathbf{i}$; the diamond-shaped registration mark indicates registration in September 1850 . Reverse as $f$.

f. One-drachm weight. Reverse as e.

g. Two-drachm weight. Reverse as h. 


\section{Drug Weighing in Britain, c. 1700-1900}

h. Two-scruple weight. Reverse as g.

i. Two-drachm weight. The designation 'Limited' indicates a later date for this weight than for the others illustrated.

j. One-drachm weight. Reverse as i.

Weights $k-n$ are examples of coin weights from the Birmingham firm P. Rogers \& Co.

k. Two-drachm weight. Most Rogers' weights do not include the address 'Birmingham'. Reverse as 1.

1. Two-scruple weight. Reverse as $\mathbf{k}$.

m. Two-drachm weight. The term 'standard' indicates production after the issuing of standards for apothecaries weights in 1879 . Reverse as $n$.

n. Two-scruple weight. Reverse as $\mathrm{m}$.

Weights $0-q$ are from an unidentified firm with the initials J.L.B.

o. Two-drachm weight. Reverse as p.

p. One-drachm weight. Reverse as o.

q. Half-drachm weight. Reverse as p.

The variety of weights $r-u$ do not bear initials or name and are probably from sources different from the above.

r. One-drachm weight. Reverse as s.

s. Two-drachm weight. Reverse as $r$. Other versions of $r$ and $s$ have crosses instead of four grouped spots in the border (cf. $t$ ).

t. Two-drachm weight. Reverse identical.

u. Two-scruple weight. Reverse identical. (Note: one cross in border not three as on t).

v. Half-drachm weight. Reverse identical. It is of interest that the maker has used the letter $f$ instead of a long $s$.

F.-x. Two unusual lozenge-shaped lead weights. One bears the denomination 120 GRS/DRA: 2, the other 407 grains.

Weights $y, z$, aa-dd are examples of circular weights which, compared with the coin-like weights above, appear to be roughly made. Weight ee is a two drachm avoirdupois weight and is included to show the possibility of confusion by using weights from the two systems when they are not adequately stamped.

y. Two-drachm lacquered weight. Reverse as $z$.

z. One-drachm lacquered weight. Reverse as y.

aa. Unusual two-scruple weight with denomination in word and Arabic numeral, and symbol. Reverse blank.

bb. Crudely-made two-drachm weight with denomination scratched and painted on-to the surface. Reverse blank.

cc. Half-drachm weight, with unusual symbol for half. Reverse inscribed t/DRAM.

dd. Half-scruple with unusual symbol for half. Reverse inscribed $1 /$ SCRU.

ee. Two-drachm avoirdupois weight with bevelled edge. Reverse blank.

Figure 6. Avoirdupois weights

Although $\mathrm{a}, \mathrm{b}, \mathrm{e}$ and $\mathrm{g}$ are not part of the contents of boxes of dispensing scales and weights, as are the other weights illustrated, they are of the type which were commonly used in the retail sale of drugs and for the preparation of large quantities of medicaments (see page 54).

The weights show good examples of many of the verification stamps frequently found on avoirdupois weights. As on fig. 4 a number of these are unidentified. Of particular interest are weights $a, f$ and $h-k$ which do not indicate the denomination of the weight, a situation which, conceivably, could have readily led to errors.

a. 4-lb. bronze bell weight (denomination not marked). The various verification stamps are the crowned monogram G (George IV); the Founders Company stamp of the ewer with the date 1826; the quartered shield of the City of London; an Oxford stamp, OXON/1834; an unidentified stamp, 11.C/1835; and the letter $\mathbf{A}$ (for avoirdupois, not a verification stamp). The base bears the letter $\mathbf{J}$ which may be a maker's mark.

b. 4-lb. brass bell weight, originally a standard for Huntingdon. Around the bottom of the weight is the statement 'BOROUGH OF HUNTINGDON/ 1st Day of January, 1826 DAVID VEASEY the younger, ESQR MAYOR'. The various verification stamps, which are often repeated, are a crowned monogram GR IV with the date 1824 (twice); the Exchequer stamp of a chequer board (twice); two Westminster stamps of a portcullis, one with the date 1824, and the other undated; and five stamps of the crowned monogram VR (Victoria) though with different outlines to the crowns. The Exchequer stamp was only applied to standards supplied to Cities and Boroughs.

c. 1-lb. flat bronze weight of the type most commonly used. The various verification stamps are the crowned monogram W (William IV); the Founders Company stamp of the ewer with the date 1826; the quartered shield of the City of London; a shield with a horse (twice), possibly a Kent stamp; and the letter $\mathbf{A}$ (for avoirdupois).

d. 4-oz. flat bronze weight with the crowned monogram V; the Founders' stamp of the ewer with the date 1826; the quartered shield of the City of London; and the letter A (for avoirdupois).

e. Two crudely-made flat lead weights of 4-oz. and 2-oz. denominations. They have no verification stamp or indication whether troy or avoirdupois. 


\section{J. K. Crellin and J. R. Scott}

f. 8-oz. flat bronze weight (denomination not marked) with stamps as on $d$ except crowned monogram G (George IV).

g. Two unusual 'cased' weights, one of 4-oz. and the other of 8-oz. The outer brass case is filled with lead (?). In relief lettering around the edge is the statement IMPERIAL STANDARD (a term which came into use after the adoption of new standards in 1824). The 4-oz. weight has, on the upper surface, the stamp $\mathrm{H} / 2$ and an indistinct mark, probably a crown. The bottom has the same mark and the statement 'cased' (twice). The 8-oz. weight has, on the upper surface, the stamps H/2. The latter weight has been 'adjusted' by the addition of lead to the base.

h. One-ounce flat bronze weight (denomination not marked). The verification marks are the Westminster stamp of the portcullis (twice).

i. One-ounce flat bronze weight (denomination not marked) with two unidentified stamps of the letters B/SM within a wavy border.

j. One-ounce flat bronze weight (denomination not marked) with two verification stamps; a crown surmounting the letter $\mathrm{H}$; and a crown surmounting the cipher WR/III. The back also bears the stamp of the crowned $\mathbf{H}$.

k. Two-ounce flat weight (denomination not marked) with words IMPERIAL STANDARD and with two verification stamps, one the crowned initials S.G and the other the barely legible crowned initials GTR/116.

Figure 7. Troy and avoirdupois weights (cf. also figure 6)

a. Set of nested brass troy weights, 8-ounce to 1-drachm. As typical of troy weights these are unstamped (see page 59). A 16-oz. weight is not included in the set.

b. Set of nested avoirdupois weights (with lid) 64-oz. to t-oz. Each is impressed on the inside base with the letter $\mathbf{A}$ and the Founders Company ewer stamp. Each weight also bears the letters AB. These are quite commonly found on weights and are believed to be the maker's initials.

c. 5-oz. troy weight from nest, bearing the crowned initial V and the City of London stamp. Post1878 stamps.

d. Unusual nest of troy weights (note TR on centre) especially designed for pharmaceutical purposes (note APOTH). Each weight stamped with crowned monogram VR and the figure 2 (indicating City of London).

e. Four-ounce troy weight (note TR) with unidentified stamp of two crowns.

f. Two-pound square iron weight with ring handle. Embossed on the surface is the statement IMPL/STAD/1826. This style of weight was commonly in use.

Figure 8. Troy weights

The weights illustrated were used for weighing coins, but as has been indicated they are quite commonly found in boxes of dispensing scales and weights and some, at least, would have been convenient for use in dispensing. Pennyweights were occasionally used for weighing materials in chemical experiments, and T. Henry when advocating his magnesia preparations in 1775 (An Account of the Medical Virtues of Magnesia Alba, more particularly of Calcined Magnesia, London, p. 28) indicated that these weights could be readily used, for weighing the preparation.

a-b. Rimmed, lozenge-shaped 6- and 4-pennyweight weights. Reverse marked with appropriate number of punch marks as on number $\mathrm{i}-1$.

c. Rectangular 2-pennyweight 16-grain weight bearing a Birmingham verification stamp of an anchor. The weight is equivalent to a post-1775 half-guinea.

d. Rectangular 5-pennyweight weight bearing a stamp of a crown, probably applied by the stamper appointed by the Crown (see page 55).

e. 12-grain weight, unusual in being made of tin not brass.

f. 12-grain weight bearing a stamp of a crown, probably applied by the stamper appointed by the Crown (cf. d).

g. Unusual 1-oz. troy weight (note TR) with bevelled edges. On the reverse is stamped D/20 (20 pennyweights).

h.-l. 5 weights showing a variety of lion stamps (cf. figure 4); e also has the Founders Company stamp of the ewer.

Figure 9. Bench dispensing scales

a. Scales of S. Maw, Son \& Thompson (1870-1901). This is of the type commonly in use through the 19th century. The pillar can be unscrewed and, with the beam and pans, packed into the drawer of the base. Note the glass pan for weighing medicaments. Ht. $37.5 \mathrm{cms}$.

One of the earliest illustrations of this type appears in a Catalogue, dating from c. 1850, of W. \& $T$. Avery \& Co. The scales are described as 'Fine Grain Scale for Surgeons, Chemists etc. Glass Pans, 8 in. Box Beam, 10 in. French Polished mahogany Box, Handsome, Brass Fittings \& Glass Pans'. Also illustrated in the :Catalogue are more robust bench scales labelled 'Drug Scales' which are freely swinging (i.e., do not have a lever and string).

We are grateful to Mr. L. Sanders of the Avery Historical Museum for drawing our attention to these illustrations.

b. Hand scales with short pillar which can be attached to the lid of the box. Probably early 19th 


\section{Drug Weighing in Britain, c. 1700-1900}

century. (Cf. footnote 5 for reference to illustration of this type of scales in Accum's A Practical Treatise on the Use and Application of Chemical Tests).

c. 19th-century scales with sliding pillar rather than string attachment as on (a). Ht. $30.5 \mathrm{cms}$.

Figure 10. Boxes of scales and weights.

a. Common oak box with dispensing scales (see appendix). The scales, with swan-neck beam, have the horn pans occasionally found on dispensing scales.

b. Japanned metal box for coin scales and weights (one weight only shown). The beam has box-ends and is uncommon in that it has plates protecting the fulcrum, a feature Nicholson reported as 'being characteristic' of scales made outside London (see footnote 63).

c. Mahogany box with label of G. Bather. The scales have ivory pans and the box has two unusual square troy weights of $\mathrm{t}-\mathrm{oz}$. and 1-oz.

d. Mahogany box of Young \& Son. This superbly-made box with its scales with silver pans has been commented on (page 63).

e. Oak box with label of William Williams. The box-end scales have copper pans, one of which is a scoop.

f. Shagreen covered wooden box for coin scales and weights. Label of Charles Sommers. The box also contains drachm and scruple apothecary weights. 
the avoirdupois weights only, there is clearly no doubt of the need for, and farreaching importance of, the reforming 1878 Weights and Measures Act. ${ }^{75}$ It is not the purpose of this paper to go into the many reforms brought about by this Act which were in addition to the introduction of inspection and verification stamping of apothecaries weights, for this can be amply seen from such publications as S. Butler's, The Weights and Measures Act, 1878 (London, 1879). The Act was only fully superseded by the 1963 Weights and Measures Act, and its importance and timeliness is therefore further reinforced when the tremendous increase in the use of potent drugs during the past few decades is realized.

\section{APPENDIX ON HAND SCALES}

The Wellcome Collections of hand scales (which include such diverse items as wooden 'butter' or farmhouse scales, ${ }^{76}$ scales with bowl-shaped copper pans, and small jewellers' scales) reflect the wide range of sizes and purposes of these readily handled and stored scales. The range of sizes of hand scales is also indicated in the scales and weights supplied to Guy's Hospital during 1725 as listed in footnote 11 .

The copper-pan scales, often called tobacco scales, were almost certainly used in chemists' and druggists' shops for retail transactions with a variety of commodities. ${ }^{77}$ However, they were usually too large, and hence insufficiently sensitive, to be used for general dispensing, so that this section is concerned with describing the much smaller hand scales used for the extemporaneous compounding of small quantities of medicaments, scales which are often confused with small scales used for other purposes. $^{78}$

Hand dispensing scales comprise part of a 'family' of small scales which include those for weighing coins and precious stones. The majority of these small balances have polished (burnished) steel beams of lengths between 10 and $15 \mathrm{~cm}$. and brass pans of diameters falling within the range 3 to $8 \mathrm{~cm}$. Relatively few scales have beams of brass, or pans of silver, glass or other non-corrosive material (see below).

The three types of small scales (for coins, precious stones, and medicines) can often be distinguished by their size. Jewellers' scales have small, shallow bowl-like pans of about 3 to $4 \mathrm{~cm}$. diameter while the pocket coin scales in small japanned iron or shagreen cases, or small wooden boxes, have flatter pans (some with turn down rims) often between 4 and $5 \mathrm{~cm}$. diameter, but more commonly between 3 and $4 \mathrm{~cm} .^{79}$ Many small dispensing scales-that is those commonly found in medicine chests-

\footnotetext{
${ }^{26}$ Pre-1878 inspection of chemists' and druggists' shops is reported in Third Report of the Commissioners Appointed to Inquire into the Conditions of the Exchequer (now Board of Trade) Standards, London, 1870, p. 50.

${ }^{76}$ The Wellcome Collections include 29 wooden seventeenth- to nineteenth-century primitive wooden scales, mostly with a pillar for standing. Three, however, are of the hand type. They are generally called butter scales.

77 Copper scales were advertised, for example, in a catalogue of medical and pharmaceutical items by Arnold's. (A Catalogue of Goods Manufactured by James Arnold, London, 1852, p. 23.)

78 A small scale, described as an apothecaries scale, but which appears to be a coin scale is illustrated by Skinner, op. cit., (footnote 3); likewise, the scales and weights reported to have been used by Garden Milne (1791-1842) in his dispensary were designed as coin scales (see Ann. Roy. Coll. Surg., 1963, 32, 314-22); Item 55 in Science Museum H.M. King George III Collection, London, 1951, could well be dispensing scales and are certainly not 'an experimental model of [a] large balance'.

70 Details of the measurements of scales in the Wellcome Collections are available on request.
} 


\section{J. K. Crellin and J. R. Scott}

are identical with the coin scales which have pans between 4 and $5 \mathrm{~cm}$. diameter, though many medicine chest scales have slightly larger pans (between 5 and $6 \mathrm{~cm}$.). However, while such coin and dispensing scales are readily identified when found in medicine chests or in the small coin scale boxes already mentioned, the larger coin and dispensing scales (for shop rather than pocket use)-and which are usually housed in rectangular oak or mahogany boxes of around 7-10 x 15-20 cm.-are not always so easy to segregate.

There are 139 examples of these larger eighteenth- and nineteenth-century boxes in the Wellcome Collections, all of wood except eight (five shagreen and three leather). ${ }^{80}$ Some of them can be readily identified as coin scales from the special compartments for coin weights and a relevant box label. However, several boxes contain both apothecary and coin weights, and, whatever the original purpose of the scales, it is clear that many were used both for dispensing and for the checking of the weights of coins, particularly gold pieces, a variety of which were in circulation, both English and foreign, at the end of the eighteenth century. Twenty-six of the 139 boxes have been designated coin scales mostly on the basis of labels and compartments for weights for coins, though with some of these the decision is a little arbitrary. ${ }^{81}$

Of the 113 'dispensing' scales in boxes several are in rather poor condition, recalling Redwood's comments about the careless way many of them were used (p. 60). Nevertheless they provide a good illustration of the type in common use. Compared with the medicine chest scales, a much higher percentage have box-end rather than swanneck beam ends ( 29 out of 113 , compared with 6 out of 252) ${ }^{82}$ The majority of these box-end beam scales are in well-made mahogany boxes (only five are in the more roughly-made oak boxes), reflecting the general superior quality and the higher cost of the former. ${ }^{83}$ Another interesting feature is that six box-end beam scales have silver pans, of which three belong to the particularly handsome boxes of Young \& Son (see p. 63). Silver pans, along with those made of such materials as ivory, glass, and horn were often used for dispensing scales (see below). One detail of these silver pan scales deserving mention is that three have beams octagonal in section (rounding towards the box-end), a type of beam also found on ten other examples with boxends, but not on those with swan-neck ends. ${ }^{84}$

Most of the dispensing scales which have swan-neck beam ends-all of which incorporate a knife edge ${ }^{85}$-are in rather crudely-made oak boxes (49 per cent of

\footnotetext{
${ }^{80}$ These shagreen and leather cased scales feature two with ivory pans. Another (c. 1820) has silver pans and a fine silver chased beam.

B1 Boxes without special compartments for coin weights, but with a label giving weights of coins, may have been primarily dispensing scales for there is some evidence that a few scale and weight makers used their stock labels indiscriminately in a variety of boxes.

B2 One of the English scales has a flat beam-end with two holes, for the suspension of the pan cord, as is typical of many continental scales.

8s Cf. prices in Arnold's Catalogue (op. cit., footnote 77).

o4 Apart from these few octagonal beams the rest of the large number of Wellcome scales have beams round or oval in section.

${ }^{83}$ This includes the late seventeenth-century scales of Henry Neale (cf. footnote 64). There is one possible exception which has a rounded pivot. While it is possible that his example is a very early scale, it is also possibly an eighteenth/nineteenth-century scale of continental origin, for a number of continental scales in the Collections are of this type.
} 
Drug Weighing in Britain. c. 1700-1900

'dispensing' boxes). Each box has a partitioned-off square compartment in one corner for weights. Only two of the boxes have a decoration (of bookbinder's tooling).

A smaller proportion (24 per cent) of the same type of swan-neck beam scales are in mahogany boxes. The boxes are of similar size and construction to those in oak, though they are more elegantly finished and, with one exception, have brass hinges in contrast with the iron wire hinges of the oak boxes.

Conspicuous among these swan-neck scales is the number with glass pans (12 per cent in oak boxes, 9 per cent in mahogany boxes). In the box-end beam scales mentioned above only 2 per cent have glass pans. (None of the scales in medicine chests has glass pans). Glass pans were recommended for medicinal substances because of their non-corroding properties. Nevertheless it must not be forgotten that they were often used for pure chemicals and for photographic materials. ${ }^{86}$ Other noncorroding pans in the oak boxes are in horn (two balances); both have the rare brass beam and appear to be from the same manufacturer. ${ }^{87}$ The Collections also have two scales (in mahogany boxes) with ivory pans (one with a swan-neck beam and one with a box-end beam).

The number of scales with non-corroding pans is thus not inconsiderable, though not so great as suggested by Kisch. Nevertheless this, nor the general absence of a ring or sight hole (cf. quotation on p. 60), does not detract from the general good accuracy of the scales as has been noted in footnote 53 .

se Two boxes, one with the label of a chemical supplier and the second with the label of a supplier of photographic equipment, are in the Collections.

" Brass-beam scales are rare in the Collections, but the few examples all have steel bushed bearings for the fulcra. 